\title{
Continuous high-resolution midlatitude-belt simulations for July-August 2013 with WRF
}

\author{
Thomas Schwitalla, Hans-Stefan Bauer, Volker Wulfmeyer, and Kirsten Warrach-Sagi \\ Institute of Physics and Meteorology, University of Hohenheim, Garbenstrasse 30, 70599 Stuttgart, Germany \\ Correspondence to: Thomas Schwitalla (thomas.schwitalla@uni-hohenheim.de)
}

Received: 20 July 2016 - Discussion started: 29 August 2016

Revised: 20 April 2017 - Accepted: 28 April 2017 - Published: 31 May 2017

\begin{abstract}
Increasing computational resources and the demands of impact modelers, stake holders, and society envision seasonal and climate simulations with the convectionpermitting resolution. So far such a resolution is only achieved with a limited-area model whose results are impacted by zonal and meridional boundaries. Here, we present the setup of a latitude-belt domain that reduces disturbances originating from the western and eastern boundaries and therefore allows for studying the impact of model resolution and physical parameterization. The Weather Research and Forecasting (WRF) model coupled to the NOAH landsurface model was operated during July and August 2013 at two different horizontal resolutions, namely 0.03 (HIRES) and $0.12^{\circ}$ (LOWRES). Both simulations were forced by the European Centre for Medium-Range Weather Forecasts (ECMWF) operational analysis data at the northern and southern domain boundaries, and the high-resolution Operational Sea Surface Temperature and Sea Ice Analysis (OSTIA) data at the sea surface.

The simulations are compared to the operational ECMWF analysis for the representation of large-scale features. To analyze the simulated precipitation, the operational ECMWF forecast, the CPC MORPHing (CMORPH), and the ENSEMBLES gridded observation precipitation data set (EOBS) were used as references.

Analyzing pressure, geopotential height, wind, and temperature fields as well as precipitation revealed (1) a benefit from the higher resolution concerning the reduction of monthly biases, root mean square error, and an improved Pearson skill score, and (2) deficiencies in the physical parameterizations leading to notable biases in distinct regions like the polar Atlantic for the LOWRES simulation, the North Pacific, and Inner Mongolia for both resolutions.
\end{abstract}

In summary, the application of a latitude belt on a convection-permitting resolution shows promising results that are beneficial for future seasonal forecasting.

\section{Introduction}

On longer timescales, like seasonal, decadal, and climate predictions, global general circulation models (GCMs) are commonly applied with a typical horizontal resolution in the range of $1-2^{\circ}$ (e.g., Taylor et al., 2012). Since it is often desired to have higher resolutions over a region of interest to better represent the land-surface interaction, more and more regional climate models (RCMs) covering only a subregion of the globe are still applied at a resolutions between 0.1 and $0.5^{\circ}$.

In the Coordinated Regional Downscaling Experiment (CORDEX; http://www.cordex.org; Giorgi et al., 2009), several RCMs are applied with grid distances of $0.44^{\circ}$ for different continental-scale regions around the globe at affordable computing power.

As this resolution still suffers from a horizontal resolution that is too coarse, e.g., the EURO-CORDEX project (http: //www.euro-cordex.net/) focuses on regional climate simulations for Europe at $0.11^{\circ}$ resolution. Evaluation studies of Kotlarski et al. (2014), Vautard et al. (2013), and Prein et al. (2015a) indicated that increasing the resolution from 0.44 to $0.11^{\circ}$ results in beneficial effects with respect to the simulation of $2 \mathrm{~m}$ temperatures with biases in the range of $\pm 2 \mathrm{~K}$. However, Kotlarski et al. (2014) show a large model variability with respect to convective precipitation during the summer season over Europe. Further, Prein et al. (2015a) show a 
strong windward-lee effect in low mountain regions in these coarse RCM simulations.

Heikkilä et al. (2011) applied the Weather Research and Forecasting model (WRF) over Norway at 0.33 and $0.11^{\circ}$, showing a superior performance of the $0.11^{\circ}$ domain with respect to precipitation and $2 \mathrm{~m}$ temperatures. Warrach-Sagi et al. (2013) performed a 20-year simulation with the WRF model over Europe at 0.33 and $0.11^{\circ}$ resolution where the focus was set on precipitation in Germany. Their study shows an overestimation of precipitation and a higher wet day frequency than observed. The $0.11^{\circ}$ simulation shows that the windward-lee effect in the low mountain ranges in Germany was also observed in a study of Schwitalla et al. (2008) who performed simulations at $7 \mathrm{~km}$ horizontal resolution using the MM5 model (Grell et al., 1995). Due to the application of a convection parameterization, convection is triggered too early with underestimated peak precipitation rates.

As $0.11^{\circ}$ resolution can still be too coarse to resolve orographic precipitation, Warrach-Sagi et al. (2013) applied the WRF model with a resolution of $0.0367^{\circ}$ during the Convective and Orographically induced Precipitation Study (COPS; Wulfmeyer et al., 2011) period in summer 2007. Their study demonstrated a significant improvement with respect to the spatial distribution of precipitation when applying a convection-permitting $(\mathrm{CP})$ resolution due to the betterresolved terrain and explicit treatment of deep convection. A better spatial distribution of precipitation was also observed in studies of Bauer et al. (2011), Prein et al. (2013), Piere et al. (2015), and Prein et al. (2015b) who clearly identified the benefit of performing convection-permitting simulations. Recently, Miyamoto et al. (2013) performed global high-resolution simulations down to the kilometer scale for a few hours due to limited computational resources. Their results clearly indicate a benefit from increasing the resolution to $\sim 3 \mathrm{~km}$ or less. Also, Palmer (2013) recommended that running climate models at a very high horizontal resolution is necessary to represent even the large-scale features like Rossby waves.

RCMs are either driven by coarser-scale models, GCMs, or coarser-scale reanalysis data like ERA-Interim (Dee et al., 2011). Therefore, the numerical solution of a RCM is driven by the lateral boundary conditions ( $\mathrm{LBCs}$ ) given by the driving model. As the inflow boundaries at coarser grid scales may be imperfect, this can deteriorate the results of the RCM. Laprise et al. (2008) suggested that RCMs require a large model domain to capture all the fine-scale features especially in the upper troposphere in the midlatitudes. Schwitalla et al. (2011) evaluated the performance of a limited-area WRF set up on a large-scale-driven precipitation event in summer 2007. The WRF model showed superior performance with respect to the representation of precipitation compared to the smaller-domain operational numerical weather prediction (NWP) model of the German Meteorological Service.

Diaconescu and Laprise (2013) tested the effect of different domain sizes on large-scale features with simulations at $\sim 0.5^{\circ}$ horizontal resolution. When RCMs are driven by LBCs containing errors, RCMs can reduce errors in the largescale circulation by applying a large model domain. Problems still can occur as the driving models often contain different physics schemes than the limited-area model (LAM), leading to inconsistencies at the boundaries which can penetrate into the model domain (Žagar et al., 2013). Becker et al. (2015) compared a 41-year simulation over Europe using a limited-area model and observed secondary circulation patterns when compared to the driving global climate model. The secondary circulation patterns appear to be the result of necessary domain boundaries when downscaling a GCM. However, these deviations should be reduced in our case, as the west-east boundaries are not present anymore. The study of remaining effects in dependence of limited-area or latitude-belt configurations can hardly be studied within our work due to the limited duration of the model runs; thus, these need to be kept for future studies.

An option to partially overcome the necessity to apply LBCs from a coarser LAM or GCM are channel or latitudebelt simulations. With these types of simulations, it is only required to apply LBCs on the northern and southern boundaries. A typical application is a tropical channel covering an area between $30^{\circ} \mathrm{S}$ and $30^{\circ} \mathrm{N}$. Due to computational constraints, these simulation often have a resolution between 20 and $30 \mathrm{~km}$ (e.g., Coppala et al., 2012; Evan et al., 2013; Fonseca et al., 2015). One idea of these special types of simulations is to allow storm systems to cross a whole ocean basin without being truncated by domain boundaries. As the general circulation is west-east oriented and lateral forcing is only applied at the northern and southern boundaries, e.g., errors in the large-scale circulation patterns can be traced back to the applied model with its specific physics schemes.

Europe is frequently affected by storm systems transiting from Newfoundland towards Europe (e.g., Rogers, 1997). By applying RCMs, western LBCs can destroy certain features of these storms before they reach Ireland and western Europe. Žagar et al. (2013) performed one of the first higherresolution latitude-belt simulations covering the Northern Hemisphere between 35 and $70^{\circ} \mathrm{N}$. They applied the WRF model for a 3-month period covering January-March 2009. The horizontal resolution was $0.25^{\circ}$ which, at this time, was very close to the horizontal resolution of the European Centre for Medium-Range Weather Forecasts (ECMWF) operational model used to force the lateral boundaries. To show the benefit of such a latitude belt, they performed additional LAM simulations with different west-east stretching domain sizes. Their results indicate a strong influence of the zonal LBCs on the internal model variability due to different model physics and the applied nesting technique. In the case that the model domain is made smaller and smaller, the RCM does not have the chance to develop its own internal variability and the results are mainly driven by the LBCs. This means that the analysis of the model errors is giving more insights into the applied model in the case of a latitude-belt setup. 


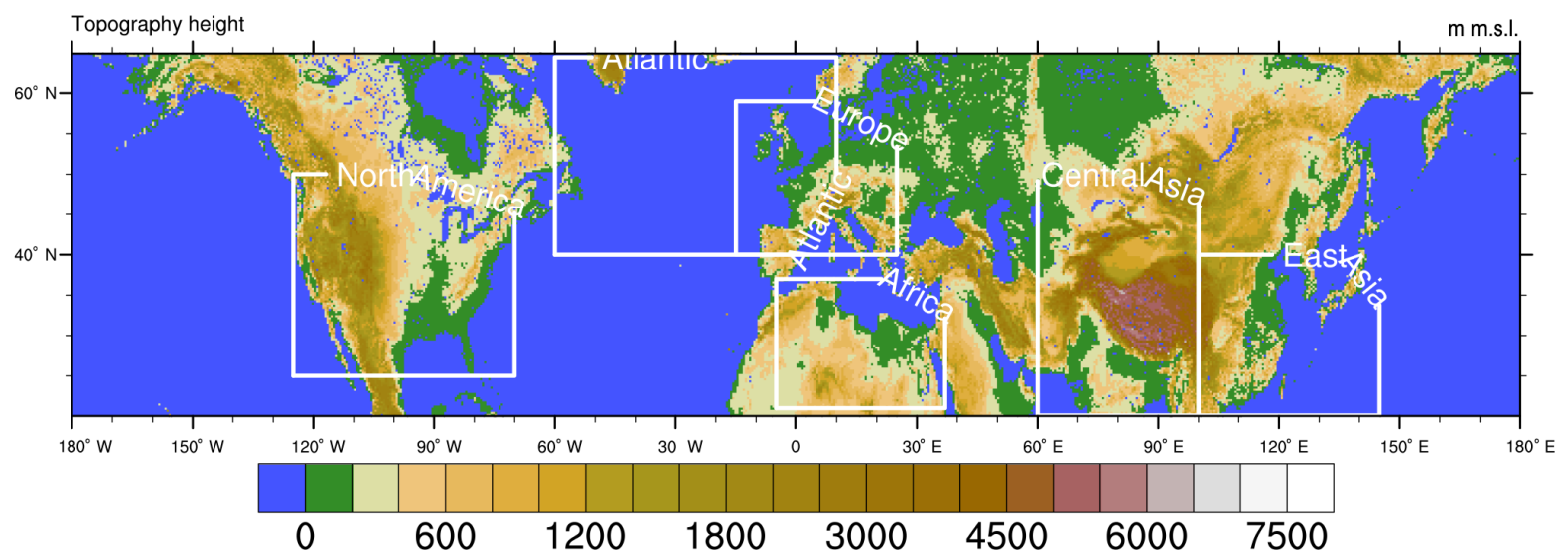

Figure 1. Model domain of the latitude-belt simulation. The white rectangles denote the domains used for verification of precipitation.

Table 1. Physics parameterizations used in the WRF simulations.

\begin{tabular}{lll}
\hline Parameterization & Scheme & Reference \\
\hline Cloud microphysics & Morrison two-moment & Morrison et al. (2009) \\
Radiation & RRTMG & Iacono et al. (2008) \\
PBL & YSU & Hong (2007) \\
Shallow convection & GRIMS & Hong et al. (2013) \\
Cumulus parameterization & KF-ETA & Kain (2004) \\
Surface layer & MM5 scheme & Jimenéz et al. (2012) \\
Land-surface & NOAH LSM & Ek et al. (2003) \\
\hline
\end{tabular}

The goal of this study is to evaluate the benefit of a unique convection-permitting latitude-belt simulation over a 2-month period which is not disturbed by zonal lateral boundaries. Due to its high computational demand, it is investigated in comparison with a lower-resolution setup as currently applied in seasonal global forecasts. The simulations were not performed in forecast mode and without data assimilation, as the study is considered a pilot study for future convection-permitting seasonal forecasting. In this study, we would like to answer whether a convectionpermitting latitude-belt simulation for a 2-month period improves the model performance compared to a commonly applied coarser resolution of $0.12^{\circ}$.

This study is organized as follows: Sect. 2.3 gives an overview about the technical details, the experimental setup, and verification strategy, followed by a review of the climatological weather situation during the simulation period in Sect. 3. In Sect. 4, a comparison of the large-scale circulation against ECMWF operational analysis followed by a comparison of $2 \mathrm{~m}$ temperatures, $10 \mathrm{~m}$ wind speeds, and precipitation will be shown. Section 5 provides a discussion of the results and Sect. 6 summarizes our results.

\section{Experimental setup}

\subsection{Model setup}

For the experiment, the limited-area WRF model (Skamarock et al., 2008) version 3.6.1 was applied. Due to the greater variety of physics options, the fully compressible, non-hydrostatic Advanced Research WRF (ARW) is used in this study. In contrast to the most commonly applied limitedarea grids, a latitude belt was selected for this study. This latitude belt covers the Northern Hemisphere between 20 and $65^{\circ} \mathrm{N}$ and is shown in Fig. 1. This is the typical latitude range for weather systems affecting Europe.

Two configurations with a latitude-longitude grid are selected: a simulation with $0.12^{\circ}$ resolution where convection was parameterized (hereafter named LOWRES) and a convection-permitting configuration consisting of $12000 \times 1500$ grid cells with a horizontal resolution of $0.03^{\circ}$ (hereafter named HIRES). The reason to choose a $0.12^{\circ}$ resolution is that the current resolution of the ECMWF operational model is similar and it is also similar to the resolution applied in the EURO-CORDEX experiment (e.g., Jacob et al., 2014).

Both simulations were performed as dynamical downscaling of the ECMWF analysis with 57 vertical levels, of which 14 levels were within the first $1500 \mathrm{~m}$ above ground level, and the model top was set to $10 \mathrm{hPa}$. The numerical time step was $10 \mathrm{~s}$ in the HIRES simulation and $40 \mathrm{~s}$ in the LOWRES simulation in order to avoid Courant-FriedrichsLewy (CFL) criteria violations in the northern part of the model domain. In addition, the epssm parameter $(\beta$ in the study of Dudhia, 1995) was set to 0.5 . This parameter biases the average in vertical wind speed for sound-wave computation, leading to an increased stability when the terrain slope is steep.

WRF-ARW offers multiple physics parameterizations. The surface layer above the ground is parameterized by the revised MM5 surface layer scheme of Jimenéz et al. (2012) 
and is combined with the Yonsei University (YSU) boundary layer scheme of Hong (2007). The YSU is widely used and extensively evaluated in the WRF community (e.g., Nolan et al., 2009; Schwitalla et al., 2011; Shin and Hong, 2011; Milovac et al., 2016).

Cloud microphysics are parameterized by the Morrison two-moment scheme (Morrison et al., 2009) which includes prognostic variables for liquid and frozen hydrometeors and their corresponding number concentrations. The Morrison scheme is a full two-moment scheme which is beneficial to represent summertime convection where frozen particles can collect liquid water. This scheme was used during summertime convective precipitation events as shown in studies by Schwitalla and Wulfmeyer (2014) and Bauer et al. (2015a).

The RRTMG longwave and shortwave schemes of Iacono et al. (2008) were applied to parameterize radiation transport. In addition to cloud water, cloud ice, and snow, RRTMG interacts with rainwater. Shallow convection was parameterized by the GRIMS scheme of Hong et al. (2013) in both simulations. At the lower boundary, the WRF model is coupled to the NOAH land-surface model (LSM) (Chen and Dudhia, 2001; Ek et al., 2003). For the $0.12^{\circ}$ simulation, the KainFritsch (KF) cumulus scheme (Kain, 2004) together with the default trigger function were applied in addition. The different physics options are summarized in Table 1.

The representation of the soil texture is crucial when performing simulations at higher resolution. Studies of WarrachSagi et al. (2008, 2013) and Acs et al. (2010) indicated that the global FAO (Food and Agricultural Organization of UNO) soil texture data set, which has a resolution of 5 arcmin (approximately $10 \mathrm{~km}$ ), shows significant deviations from high-resolution soil databases. When approaching the convection-permitting scale, a soil texture data set with the corresponding resolution is required since the texture determines the soil moisture. We used a modified soil texture data set from Milovac et al. (2014), which is derived from the Harmonized World Soil Database (HWSD) between $60^{\circ} \mathrm{N}$ and $60^{\circ} \mathrm{S}$, available at $1 \mathrm{~km}$ resolution. Land cover is described by the 20-category MODIS data set from the International Geosphere Biosphere Programme (IGBP) program available at 30 arcsec resolution.

The model setup applied in this study is very similar to a seasonal forecast system and can be seen as a single realization of a such a forecast ensemble with different resolutions. The operational model of ECMWF was upgraded to cycle $38 \mathrm{r} 2$ in 2013. This upgrade includes a change in vertical resolution from 91 to 137 levels with a densification especially in the lowest $1500 \mathrm{~m}$ above the ground. This increase in vertical resolution becomes more and more important with increasing horizontal resolution. The simulations were performed for a 2-month period starting at 1 July 2013 00:00 UTC.

Forcing data at the northern and southern boundaries were provided by 6-hourly ECMWF operational analysis data on model levels and are blended with the default linear decay over five grid points into the WRF model grid. Sea surface temperatures (SSTs) were provided by the high-resolution Operational Sea Surface Temperature and Sea Ice Analysis (OSTIA) data (Donlon et al., 2012) with a resolution of $\sim 5 \mathrm{~km}$. As this study only contains a small part of the tropics, it appears practicable to use more or less constant SST data for each day. As they are only available in daily intervals, these data were linearly interpolated to the $6 \mathrm{~h}$ intervals of the ECMWF analysis. This interpolation was performed by using version 1.7.0 of the Climate Data Operators (CDO; https://code.zmaw.de/projects/cdo). Analysis nudging was not applied in our experiments, as this study is considered as single realization of a seasonal forecasting ensemble, and we consider this as a more straightforward approach to identify the causes of model errors.

Soil moisture and temperature were initialized from the ECMWF operational analysis. The hydrology land-surface model HTESSEL (Balsamo et al., 2009) has assimilated ASCAT soil moisture data since 2012 (Albergel et al., 2012). A brief comparison of the analyzed ECMWF soil moisture and HIRES soil moisture data over Europe revealed no major differences between both data sets during the first 17 forecast days. The absolute soil moisture content in the three topmost layers is between 0.25 and $0.3 \mathrm{~m}^{3} \mathrm{~m}^{-3}$, and the differences between HIRES and ECMWF vary around $0.05 \mathrm{~m}^{3} \mathrm{~m}^{-3}$. This is very promising especially as ECMWF has assimilated ASCAT soil moisture data since 2012 (Albergel et al., 2012). Thus, it appears feasible to waive a separate spin-up run for this 2-month period. Afterwards, the soil moisture shows a different behavior most probably due to different evapotranspiration and precipitation patterns.

\subsection{Verification data strategy}

Obtaining consistent observations of wind, temperature, and moisture at different altitudes, which are at a comparable resolution to $0.12^{\circ}$, is currently very challenging. They are only available for a few countries and are not homogeneous. Satellite-derived products like integrated water vapor, radiation data, and cloud products are not available at the required resolution and spatial and temporal coverage. Therefore, the operational ECMWF analysis provides the basis to analyze the results of both WRF simulations with respect to the largescale patterns, apart from precipitation, where more suitable data sets are available.

The ECMWF analysis is generated by a four-dimensional variational data assimilation system (4D-Var; Rabier et al., 2000). It combines a model background field from a previous forecast with high-resolution observations in order to obtain a high-quality gridded analysis field. The 4D-Var at ECMWF includes several different observation types like surface measurements, radio soundings, satellite radiances, and aircraft measurements. Regridding of WRF pressure level output to the ECMWF grid at $0.125^{\circ}$ was performed with an Message Passing Interface (MPI)-compiled version of the Earth System Modelling Framework (ESMF) Regrid- 
WeightGen tool (https://www.earthsystemcog.org/projects/ regridweightgen/) within the NCAR Command Language (NCL) framework using bilinear interpolation. ECMWF reanalysis data (Dee et al., 2011), available on a $0.75^{\circ}$ grid, are applied for evaluations within CORDEX (e.g., Vautard et al., 2013; Warrach-Sagi et al., 2013).

We also tried conservative remapping using the ESMF regridding function, as the native ARW grid is not fully supported by the CDO. Unfortunately, this procedure violates the NetCDF format constraints due to additional variables stored in the weighting file for this huge domain. This means that the regridding routines from ESMF and CDO have to be rebuilt with NetCDF4 support which is beyond the scope of this work. According to a study of Jones (1999), the conservative remapping method maintains the integral of the interpolated variable but may introduce larger interpolation errors which can introduce artificial variability.

Standard deviation, bias, and root mean square error (RMSE) were calculated on a daily basis using the dim_rmsd_n and dim_stat_4_n functions of NCL by comparing the 12:00 UTC time steps for each day. The scores are finally averaged over the 2 -month period. In order to show that both WRF simulations do not deviate too far from the operational analysis, the mean sea level pressue (MSLP) and $500 \mathrm{hPa}$ geopotential height bias are expressed in terms of standard deviations of the analysis fields during each month to verify that the bias of both WRF simulations stays within \pm 2 standard deviations of the analysis.

Following the study of Kotlarski et al. (2014), who evaluated a 20-year evaluation run ensemble, a mean sea level pressure bias of $3 \mathrm{hPa}$ is acceptable. For temperature, mean deviations of up to $3{ }^{\circ} \mathrm{C}$ are tolerable in homogeneous terrain, while for precipitation relative differences of $100 \%$ are reasonable. In the case of very low precipitation amounts, like in north Africa, relative deviations of more than $100 \%$ are tolerable.

For the verification of precipitation, the CPC MORPHing technique (CMORPH; Joyce et al., 2004) data set was applied. It is an almost global precipitation analysis, based on low-orbit microwave satellite data. In version 1.0, this product is bias corrected and also uses surface precipitation data where available (blended product). The daily precipitation analysis is available on a $0.25^{\circ} \times 0.25^{\circ}$ grid. Studies of, e.g., Liu et al. (2015) and Stampoulis et al. (2013) show a reasonable correlation of the CMORPH precipitation analysis with ground stations in different regions around the globe. A study of Gebremichael et al. (2014) indicated that although weaknesses in satellite-derived precipitation products exist over the mountains, CMORPH performs considerably better than products from the Tropical Rainfall Measuring Mission (TRMM) (Huffman et al., 2007). In order to compare the observations with the simulations, the HIRES and LOWRES data were interpolated to the CMORPH grid using the ESMF regridding routines. Additionally, the operational $24 \mathrm{~h}$ fore- cast of the 00:00 UTC forecasts from ECMWF is applied to classify the WRF precipitation forecasts.

A recent study of Skok et al. (2016) showed a superior performance of the E-OBS data (Haylock et al., 2008) over Europe compared to the CMOPRH observations. Therefore, the E-OBS precipitation data set was selected for comparisons in Europe. To perform the interpolation to the corresponding observation grid, the ESMF tools within NCL have been applied in the same way as for the interpolation of the WRF output to the ECMWF grid. The RMSE and biases, with respect to the CMORPH and E-OBS data sets, are calculated from the 2-month accumulated precipitation over the whole observation domain.

In addition to the traditional scores, the Perkins skill score (PSS; Perkins et al., 2007) was applied for the validation of the mean sea level pressure and European precipitation data. The PSS measures the overlap of two probability density functions (PDFs) by calculating the cumulative minimum value of each binned variable. In the case that both PDFs show an ideal overlap, the PSS would be equal to 1 . If there is no overlap between both PDFs then the PSS would be 0 . The PSS is calculated for each grid and finally averaged over the corresponding subdomains in order to keep a large number of samples to calculate the PDFs as suggested by Perkins et al. (2007).

As both WRF simulations are performed without the aid of data assimilation, it cannot be anticipated that they represent single extreme weather events. Nevertheless, both simulations are expected to reproduce the large-scale weather situation with advantages when applying a convection-permitting resolution. The main goal of this study is to compare the different resolutions relative to each other rather than specifying whether a certain bias is acceptable.

\subsection{Computational aspects}

The WRF model simulations were performed at the High Performance Computing Center Stuttgart (HLRS) on the Cray XC40 (http://www.hlrs.de/systems/ cray-xc40-hazel-hen/). At the time when the simulations were performed, the system consisted of approximately 4000 compute nodes each equipped with two Intel 12-Core CPUs with $2.5 \mathrm{GHz}$ clock frequency. The model was compiled with version 14.7 of the Portland Group compiler, Cray MPI 4.3.2, and Parallel NetCDF 1.5.0. The total number of cores was partitioned in such a way that each node was filled with four MPI tasks and six OpenMP threads so that in total 14000 MPI tasks were used.

The Lustre file system was configured so that 128 object storage targets (OSTs) were used for writing into a single NetCDF file of 92 GB for the HIRES simulation. Further testing revealed that it was not beneficial to use more MPI tasks, as this deteriorated the $\mathrm{I} / \mathrm{O}$ rate which was in the range of $\sim 6-7 \mathrm{~GB} \mathrm{~s}^{-1}$. The total data amount including restart files for the HIRES simulation is about $300 \mathrm{~TB}$. 
The necessary input fields from the ECMWF analysis and required high-resolution SST data are about $465 \mathrm{~GB}$ in size. It has to be noted that due to limitations in the WRF preprocessing system (WPS) code of the WRF model system, each GRIB2 file has to be smaller than $2 \mathrm{~GB}$; otherwise, this file cannot be fully read in by the ungrib program. The time required to download and process these data is about 3 days.

As the Metgrid interpolation program requires a lot of memory and does not support Parallel NetCDF, the input fields had to be split using a value of 102 for io_form_metgrid in namelist.wps so that each MPI task writes its own small NetCDF file. These files were ingested into the Real program using io_form_input $=102$ in the namelist.input and the required wall time for Real was about $24 \mathrm{~h}$. The used namelist.input for the HIRES simulation is shown in the Supplement.

For the HIRES simulation, 3500 compute nodes (84000 cores) were used for 3.5 days wall time resulting in $\sim 0.15 \mathrm{~s}$ for each model time step, increasing the speed by a factor of 66 compared to real time. The $0.12^{\circ}$ simulation was performed on 120 compute nodes and was finished within $31 \mathrm{~h}$ wall time.

If such a high-resolution simulation is considered for operational applications, users have to reduce the output frequency considerably as otherwise the time for writing the files becomes the prevailing process. If even a higher number of grid points is planned for use, one has to take care of the NetCDF limitations in the commonly used CDF-2 format. This convention only allows $2^{32}-4$ bytes per array which can be too small for future experiments so that the new CDF-5 standard has to be considered. This feature is available from PnetCDF version 1.6.0 onwards.

In order to have the possibility to run a largedomain latitude-belt simulation on the $\mathrm{CP}$ scale, we modified the source code by exchanging the second argument of the $\mathrm{nf}$ _create function from NF_64BIT_OFFSET to NF_64BIT_DATA in frame/module_bdywrite.F. A similar change was performed in external/io_pnetcdf/wrf_io.F90. In the NFMP I_CREATE function, the third argument has to be replaced by NF_64BIT_DATA. In the NFMPI_OPEN function, NF_NOWRITE has to be replaced by NF_WRITE.

Another alternative is to use NetCDF4 with HDF5 support but due to the applied compression, this may require the same time for writing, although the file sizes may be considerably smaller than with classic NetCDF. Further information about technical challenges can be found in Bauer et al. (e.g., 2015b).

\section{Seasonal statistics}

In order to classify the meteorological conditions of summer 2013, climatologies from the ERA-Interim analysis (Dee et al., 2011) were analyzed. Figure 2 displays the mean
$500 \mathrm{hPa}$ geopotential (solid lines) together with the anomaly of July and August 2013 compared to 1979-2012 (shaded). It shows the Azores high with a geopotential height of more than 5900 gpm over the central Atlantic which is in accordance with the climatological mean of 1979-2012.

Over the northern midlatitudes, a positive anomaly of the $500 \mathrm{hPa}$ geopotential height is observed over Newfoundland, the western United States, and the northern Pacific, while the $500 \mathrm{hPa}$ geopotential height is significantly higher than the climatological mean, especially over Europe. In connection with lower geopotential values over Greenland, this leads to stronger wind speeds in the middle troposphere and thus changes the circulation patterns compared to the climatology. The stronger gradient in the $500 \mathrm{hPa}$ geopotential between the northern Pacific and east Asia supports the transport of warm and moist air masses towards north and east Asia, especially as the SSTs are higher than the climatological average during both months (Fig. 3). The location of the jet stream is similar during the simulation period as compared to the climatology. The most remarkable difference is the considerably increased wind speed east of Newfoundland and over central Asia while the wind speeds are weaker over the $\mathrm{Pa}$ cific (not shown).

The mid-troposphere high extends further towards central Europe and is also visible at the surface. Figure 4 shows the average MSLP (contour lines) for the 2-month period together with the corresponding anomalies (shaded). The MSLP anomaly reaches $3 \mathrm{hPa}$ over central Europe, while at the same time the MSLP bias is negative between Greenland and Iceland, leading to higher low-level wind speeds than normal. July and August 2013 were characterized by a strong positive North Atlantic Oscillation (NAO) index of 0.7 and 1.0 in July and August, respectively. Apparently, the positive SST anomalies (Fig. 3) around $2.5^{\circ} \mathrm{C}$ over the central Atlantic and the northern Pacific are responsible for the lower MSLP over the North Atlantic and the eastern Pacific as compared to the climatology. Particularly in Europe, there was a heat wave in July, leading to dry conditions in western Europe (Dong et al., 2014). The precipitation amounts over central and northern Europe were less than $50 \%$ of the climatological mean as indicated by the E-OBS (Haylock et al., 2008) precipitation data set (not shown).

\section{Results}

\subsection{Large-scale circulation}

Figure 5 shows the comparison of the averaged MSLP at 12:00 UTC for July and August 2013. In July, the ECMWF model shows a strong high-pressure system over the eastern Pacific and a well-defined high-pressure system over the Atlantic. This is a typical situation during summer over the Northern Hemisphere (see Fig. 4). 


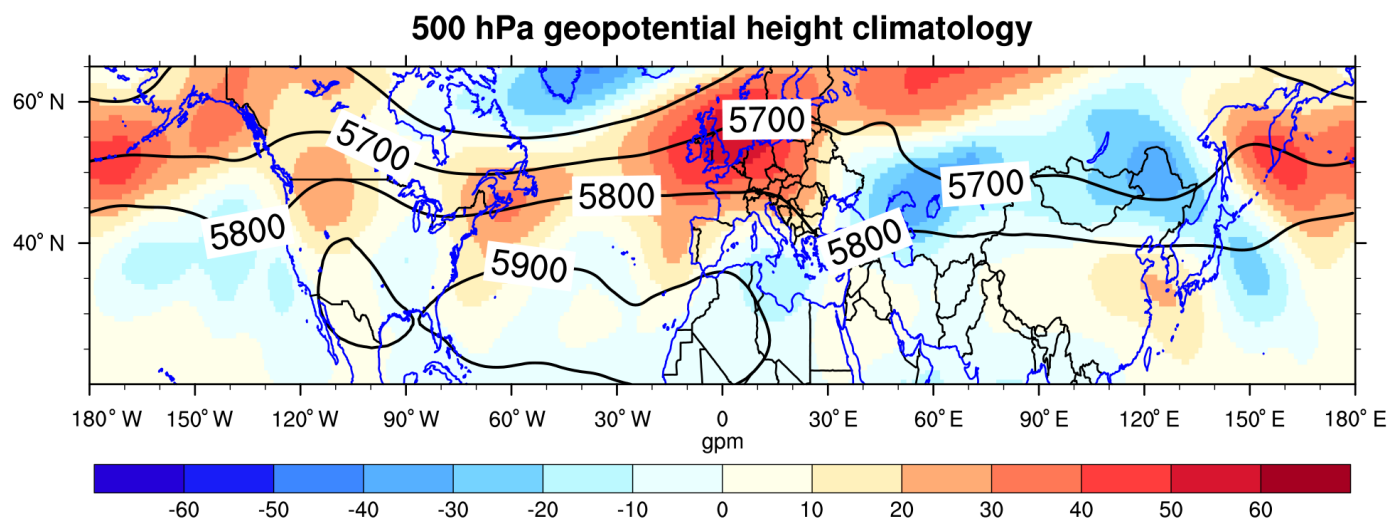

Figure 2. ERA-Interim $500 \mathrm{hPa}$ geopotential height climatology for July and August 2013 (black solid lines). The shaded areas show the anomaly during July and August 2013 compared to the period 1979-2012.

\section{(a) SST anomalies July 2013}

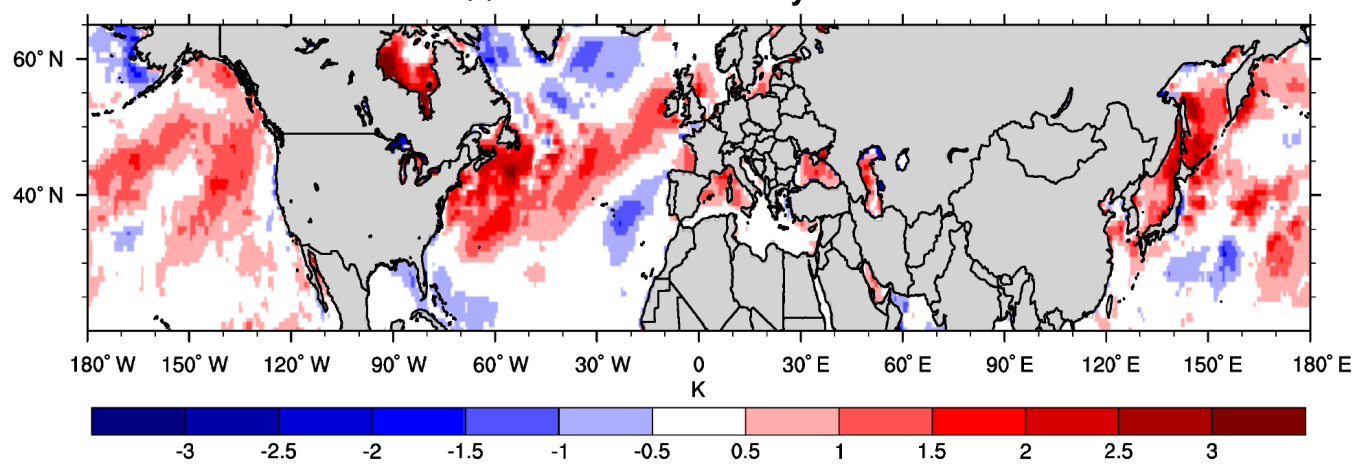

(b) SST anomalies August 2013

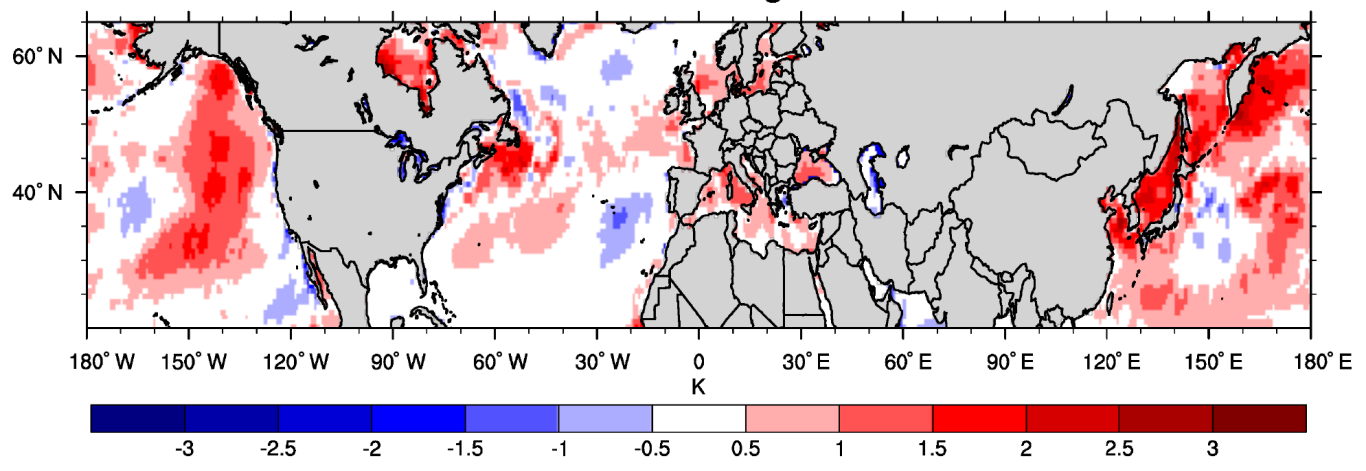

Figure 3. ERA-Interim sea surface temperature (SST) anomalies in July 2013 (a) and August 2013 (b) compared to the climatological period 1979-2012.

During July, both WRF simulations are able to capture the general features compared to the ECMWF analysis. Larger differences occur over the Pacific Ocean and over the central Atlantic where the high-pressure systems are located. The intensity of the Pacific high is significantly overestimated in both simulations (Fig. 5g, i) and its location is slightly shifted to the south showing a dipole structure. This behavior was also observed in a study of Cassano et al. (2011) who performed month-long simulations using WRF over the polar and subpolar regions.
The PSS of the MSLP over Europe for the HIRES simulation is 0.91 for July and 0.9 for August 2013, whereas the LOWRES simulation yields values of 0.92 and 0.86 for July and August, respectively. Perkins et al. (2007) and Devis et al. (2013) suggest that a PSS of 0.7 indicates a reasonable model performance when compared to reference data sets. Therefore, the achieved scores indicate a good performance of both WRF simulations over Europe with better results in the HIRES simulation on longer forecast lead times. 


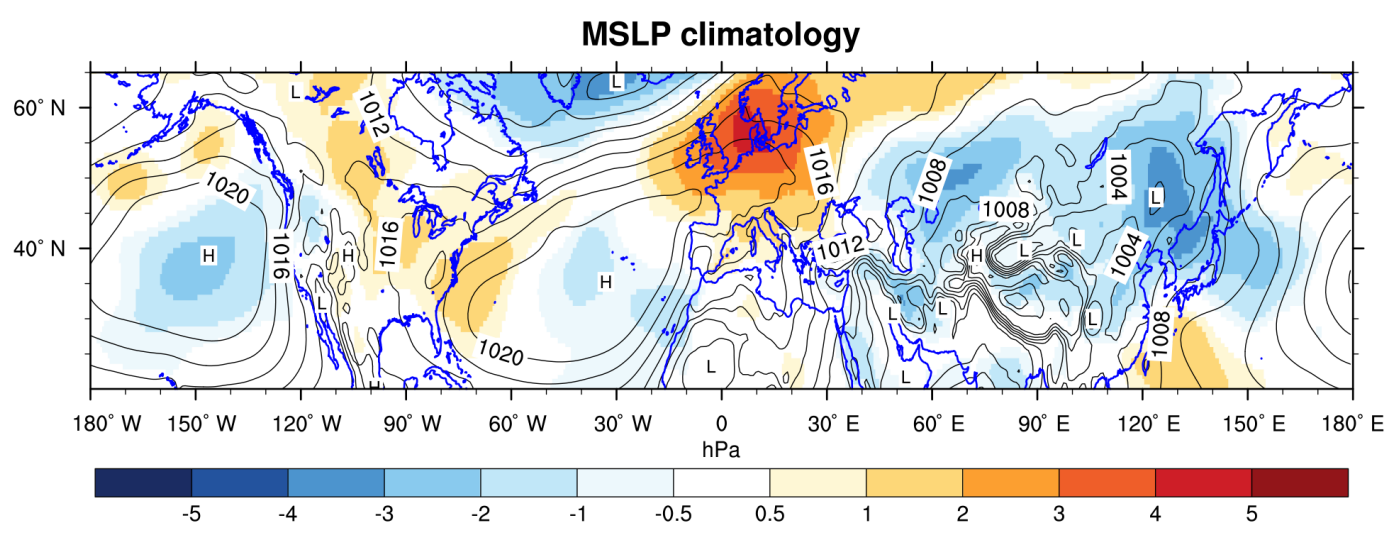

Figure 4. Mean sea level pressure climatology for July and August 2013 (black solid lines) from ERA-Interim. The shaded areas show the anomaly during July and August 2013 compared to the period 1979-2012.

In both simulations, the Atlantic high-pressure system extends further to the north towards the Azores, and also the intensity is overestimated, as compared to the ECMWF analysis. The LOWRES simulation shows a negative bias east of Greenland. This is not seen in the HIRES simulation which is in a better accordance with the ECMWF analysis.

During August 2013 (right column of Fig. 5), the Pacific high is still overestimated with a bias of more than $5 \mathrm{hPa}$ (Fig. 5h, j) and the high-pressure system over the Atlantic shows a different shape compared to the ECMWF analysis (Fig. 5b, d, f). The strong negative bias over central Asia is the result of too-high $2 \mathrm{~m}$ temperatures (see Sect. 4.3).

To further assess the quality of the simulation, Fig. 6 shows the confidence of the WRF simulation biases expressed in terms of ECMWF standard deviations for MSLP and $500 \mathrm{hPa}$ geopotential height, indicating that the bias mostly stays within \pm 2 standard deviations of the ECMWF analysis for both variables. The mean value of the deviation expressed in terms of ECMWF standard deviations for the MSLP is 0.22 and 0.36 (HIRES) and 0.29 and 0.43 (LOWRES) for July and August, respectively. For the deviations of the $500 \mathrm{hPa}$ geopotential height, the values are 0.21 and 0.24 (HIRES) and 0.21 and 0.31 (LOWRES), respectively.

Both WRF simulations show different sensitive regions compared to ECMWF, as indicated by the MSLP standard deviation shown in Fig. 7 for the different months. The LOWRES experiment exhibits an unrealistically large variability over the Hudson Bay in July associated with a stronger variability of the $850 \mathrm{hPa}$ wind speeds (not shown). The large standard deviation over the North Atlantic shown by the HIRES simulation can be explained by a higher internal variability due to the higher resolution. Such variability cannot be expected in the ECMWF analysis due to its coarser resolution which does not resolve the corresponding high-resolution dynamical processes.

Especially in August, the LOWRES simulation tends to exaggerate the development of tropical storms, as indicated by the large standard deviation of more than $12 \mathrm{hPa}$ south of Japan. Apparently, this is related to the stronger pressure gradient over the west Pacific (Fig. 5). According to the analysis of the Japanese Meteorological Agency (JMA; http: //www.jma.go.jp/en/typh/), only two tropical storms were present during August in the west Pacific north of $20^{\circ} \mathrm{N}$.

Figure 8 shows the mean $300 \mathrm{hPa}$ wind speed of both WRF simulations compared with the ECMWF analysis for 12:00 UTC. During both months, the ECMWF analysis (Fig. 8) shows a well-defined subtropical jet stream north of the Tibetan Plateau with an average wind speed of $30 \mathrm{~m} \mathrm{~s}^{-1}$ over central Asia, which is typical for the monsoon season (e.g., Xie et al., 2015). Also, the polar jet over the Pacific and Newfoundland is clearly visible. Compared to the climatology from 1979 to 2012, the positions of the subtropical and polar jets are very similar, with considerably higher wind speeds along the subtropical jet.

The large-scale structure is captured in both WRF simulations, while the HIRES simulation shows a weaker maximum over central Asia as compared to ECMWF. Both WRF simulations tend to overestimate the intensity of the subtropical jet over the North Pacific, but the HIRES simulation has a lower RMSE as compared to the LOWRES experiment (not shown). At the $200 \mathrm{hPa}$ level (not shown here), the wind maximum over central Asia is simulated more accurately in the HIRES simulation. This indicates a possible influence of the better-resolved terrain over Asia. As the surface low over the Tibetan Plateau is deeper than observed, this can induce a force which moves the subtropical jet to the north, deforming it, as shown by the light red colors over the northwest of China and Mongolia in Fig. 8. In addition, the better representation of the Pamir and Tian Shan mountains in the higher-resolution model also plays a role in terms of blocking southward movement of the jet.

To complement the results for the large-scale circulation, Fig. 9 shows the mean $500 \mathrm{hPa}$ geopotential height of the ECMWF analysis at 12:00 UTC time steps. Here, a wavelike structure with 5-6 stationary waves is visible during both 

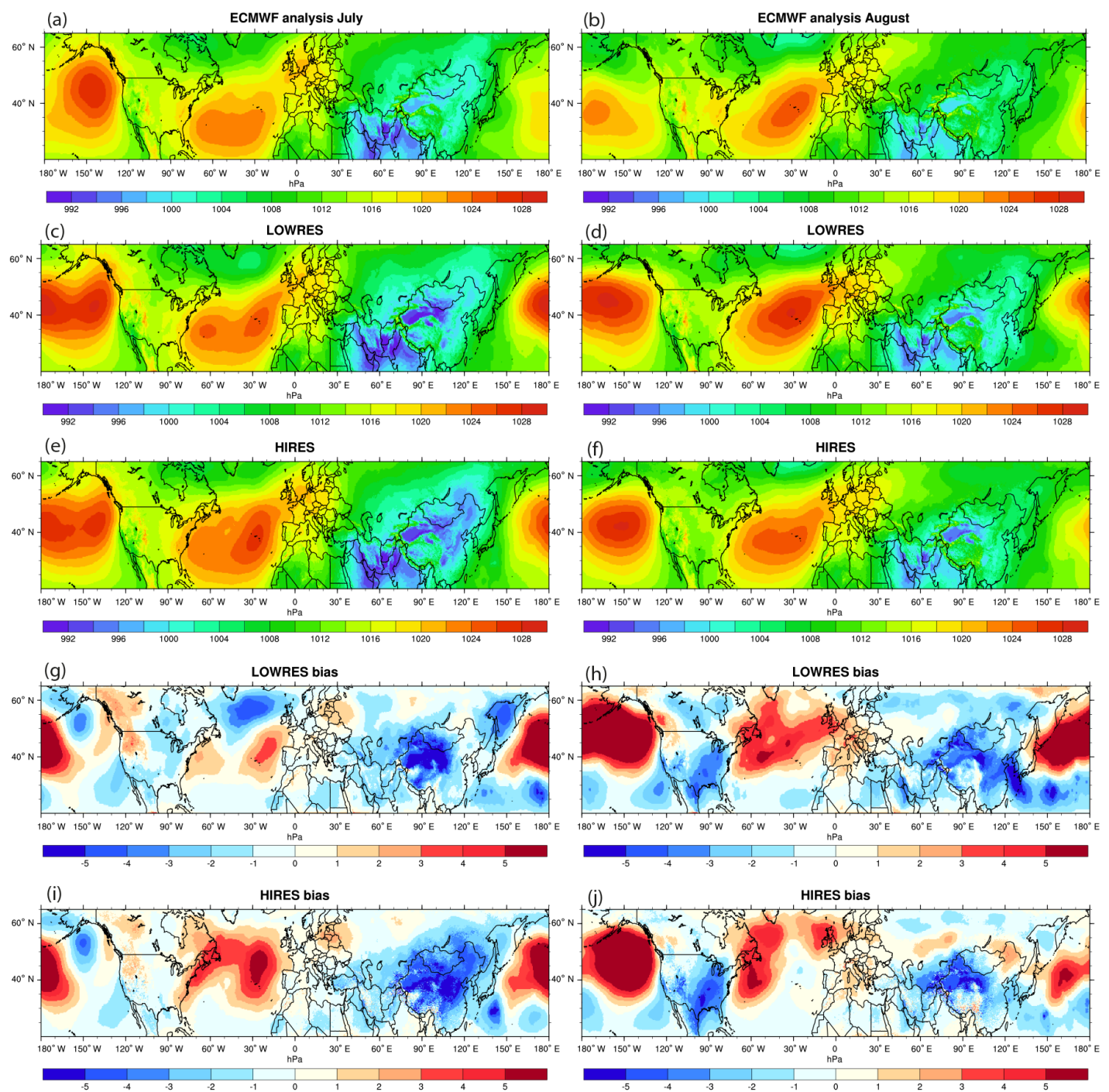

Figure 5. Average mean sea level pressure and mean difference between the WRF simulations and ECMWF analysis at the 12:00 UTC time steps for July 2013 and August 2013. The first row shows the ECMWF analysis (a, b) followed by the LOWRES simulation (c, d) and the HIRES simulation $(\mathbf{e}, \mathbf{f})$. The two lowermost rows show the mean bias for the LOWRES $(\mathbf{g}, \mathbf{h})$ and the HIRES simulations (i, $\mathbf{j})$ compared to the ECMWF analysis for the two different months.

months in the analysis indicated by the alternating light red and dark red colors.

In July, the general features agree in both WRF simulations and the differences partially reflect the displacement of the low-pressure systems shown in Fig. 5. The LOWRES simulation simulates high geopotential over Mongolia and the west Pacific in July 2013 as compared to the ECMWF analysis. This bias further increases in August 2013, exceeding $100 \mathrm{gpm}$ over the North Pacific and Newfoundland (Fig. 9d) as a result of the even stronger displacement of the pressure systems, similar to the results of Cassano et al. (2011). The HIRES simulation also simulates high geopotential at $500 \mathrm{hPa}$ over the Atlantic but the differences over the west Pacific are much smaller in August 2013 compared to the LOWRES simulation.

In addition, Fig. 10 shows the time series of the averaged MSLP over the North Atlantic between 40 and $65^{\circ} \mathrm{N}$ and $60^{\circ} \mathrm{W}$ and $10^{\circ} \mathrm{E}$ (white rectangle marked "Atlantic" in Fig. 1). During the first $\sim 10$ days, the HIRES simulation (red line) agrees well with the ECMWF analysis, while the LOWRES simulation shows slightly lower pressure values. After this period, the LOWRES simulation shows considerably lower MSLP compared to the ECMWF analysis while the HIRES simulation is much closer the ECMWF analysis until day 18 of the forecast where both simulations miss the development of a depression. Both simulations are able to capture the pressure drop after 25 days of forecast but 

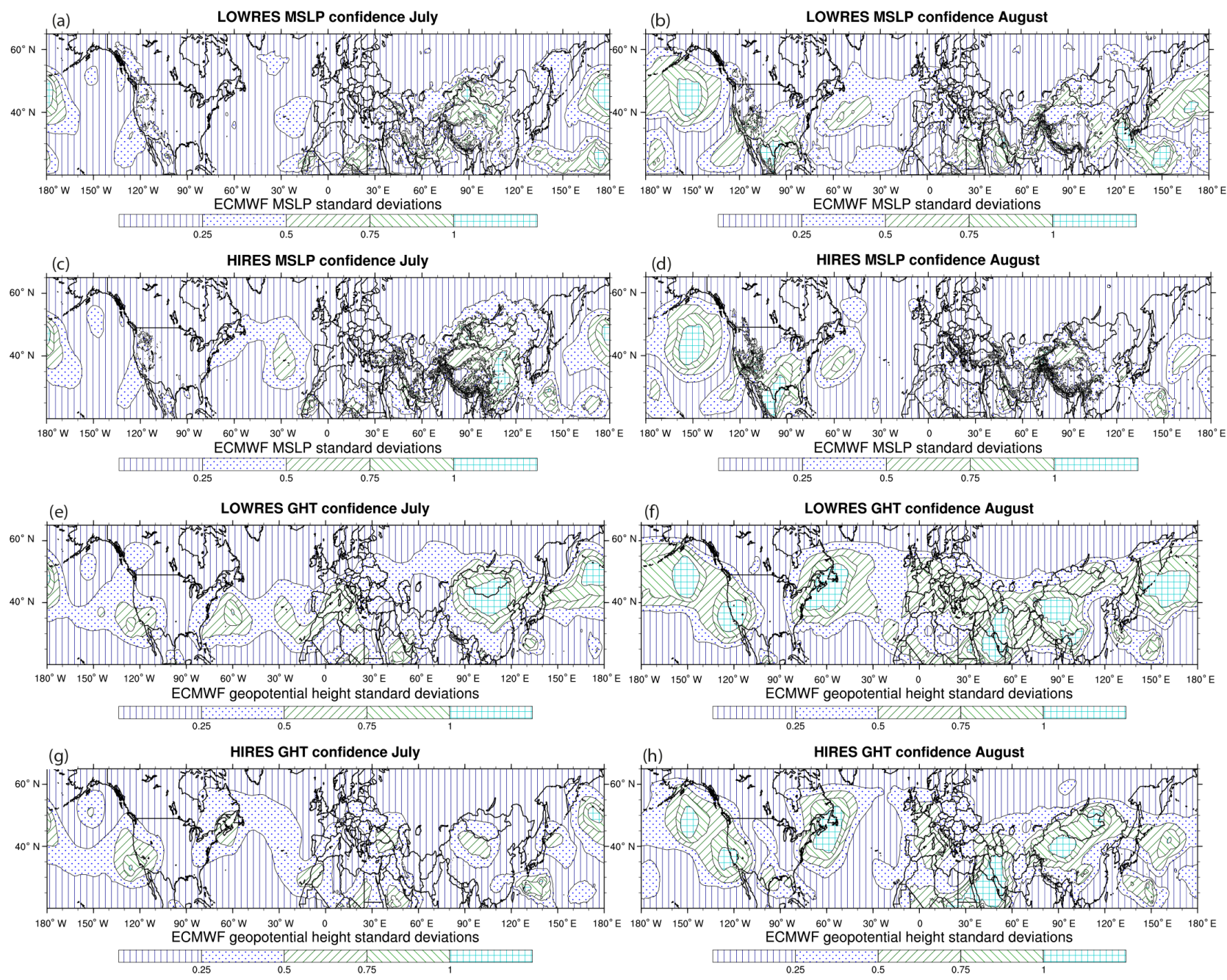

Figure 6. Model biases expressed in absolute terms of 2 ECMWF standard deviations for the LOWRES simulation (a, b, e, f) and the HIRES simulation (c, $\mathbf{d}, \mathbf{g}, \mathbf{h})$ for the 12:00 UTC time steps. Left column: July 2013. Right column: August 2013. First two rows: mean sea level pressure. Bottom two rows: $500 \mathrm{hPa}$ geopotential height.

the HIRES simulation shows a better agreement with the ECMWF analysis. In the following, both WRF simulation overestimate the strength of the high-pressure situation as being closer to the analysis again after 45 days. Overall, the LOWRES simulation shows a tendency to even further overestimate the strength of low- and high-pressure systems.

The mean bias of the HIRES simulation during July is $1.6 \mathrm{hPa}$, while it is $-0.8 \mathrm{hPa}$ for the LOWRES simulation. In August, the bias of the HIRES simulation stays the same, while for the LOWRES simulation it turns into a positive bias of $2.2 \mathrm{hPa}$. The root mean square error during July is 4.5 and $4.65 \mathrm{hPa}$ for the HIRES and LOWRES simulations, respectively. It further reduces to 3.5 (HIRES) and $3.65 \mathrm{hPa}$ (LOWRES) during August 2013.

\subsection{Temperature and moisture in the lower troposphere}

The moisture availability in the boundary layer is an important factor for the development of convection and precipitation. As an example, Fig. 11a shows the mean $925 \mathrm{hPa}$ water vapor mixing ratio of the ECMWF analysis at 12:00 UTC. The areas with high moisture content over India during the monsoon season and the low amount of water vapor over continental Africa and the African west coast can be recognized by the greenish and blueish colors.

From Fig. 11 it is seen that WRF estimates a higher moisture content over the central Pacific with a strong bias of $\sim 1.5 \mathrm{~g} \mathrm{~kg}^{-1}$. The same holds for the Gulf of Mexico and the western Atlantic. There are only minor differences in the moisture content at $925 \mathrm{hPa}$ north of $45^{\circ} \mathrm{N}$ due to small differences in the MSLP field. Both simulations show similar 

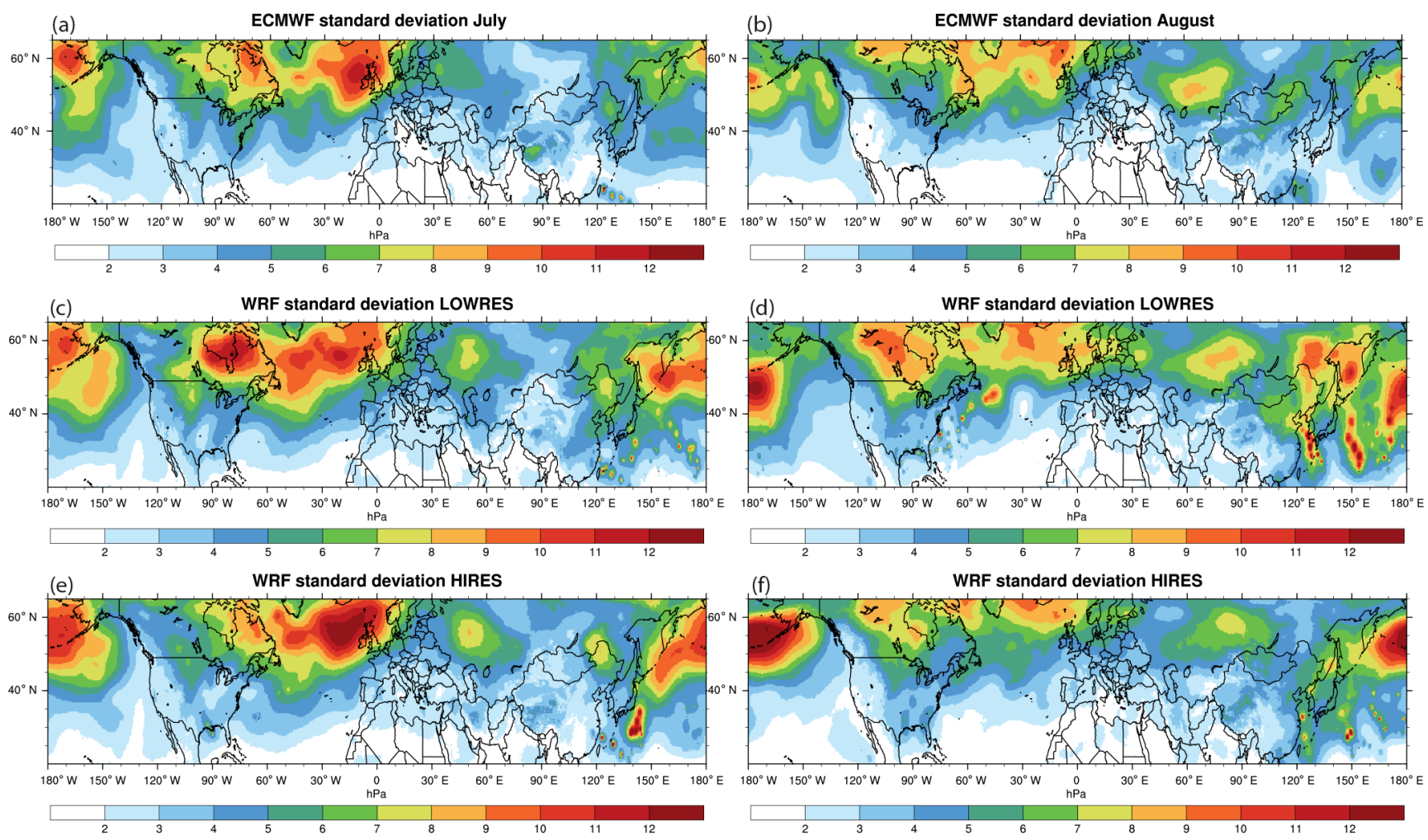

Figure 7. Mean sea level pressure standard deviation at 12:00 UTC for July 2013 (a, c, e) and August 2013 (b, d, f). The top row shows the ECMWF analysis, the middle row shows the LOWRES simulation, and the bottom row displays the HIRES simulation.

RMSE values of $\sim 2.4 \mathrm{~g} \mathrm{~kg}^{-1}$ with an improvement of about $5 \%$ in the HIRES simulation (not shown). The largest deviations from the ECMWF analysis occur on the east coast of Canada, the North Atlantic, and the west Pacific, which are the regions with the highest pressure deviations, as these are the areas where the low-pressure systems develop. The higher moisture values at the North American east coast can be related to the transportation of humidity from the Gulf of Mexico due to the more intense high-pressure system over the Atlantic, leading to a stronger southwesterly flow in the lower troposphere. This behavior is sustained at $850 \mathrm{hPa}$ where a similar pattern is observed.

The upper panel of Fig. 12 shows the mean temperature of the ECMWF analysis at $925 \mathrm{hPa}$. The warm air masses transported from the desert towards the Atlantic due to trade winds can be identified. The LOWRES simulation (Fig. 12b) shows a very strong positive temperature bias exceeding $3 \mathrm{~K}$ over Europe, north Africa, and the northwest Pacific. The HIRES simulation also shows a positive temperature bias but it is less pronounced than in the LOWRES simulation, and the bias over the northwest Pacific is significantly reduced by about $2 \mathrm{~K}$.

The temperature bias over Newfoundland is caused by the inaccurate position of the Atlantic high-pressure systems which extend too far to the west (see Fig. 5). Due to the different wind direction, warmer air masses from the Gulf of Mexico are advected towards Canada. Another interesting feature is the strong overestimation of $925 \mathrm{hPa}$ temperatures in both WRF simulations on the west coast of California. This is due to an overestimation of wind speeds associated with the stronger pressure gradient which dries out the air coming from Cascade Mountain.

In general, the LOWRES simulation shows an even higher temperature bias exceeding $5 \mathrm{~K}$ over the North Pacific (Fig. 12b). Note that the average RMSE in the HIRES simulation over Europe is very small with around $3 \mathrm{~K}$ at 925 and $850 \mathrm{hPa}$ (not shown). Further, the LOWRES simulation does not simulate the tongue of cold air extending from the central North Atlantic towards the west of the Canary Islands (indicated by the warm bias south of the Azores in Fig. 12b). The LOWRES simulation tends to overestimate the boundary layer wind speeds in combination with the spatial shift of the high-pressure system. Due to the strong high pressure over the Atlantic and the resulting subsidence, warm air masses are transported from the African desert towards the Canary Islands. In addition, the insufficient representation of the terrain in the LOWRES simulation can lead to a different circulation pattern than in the HIRES simulation. 

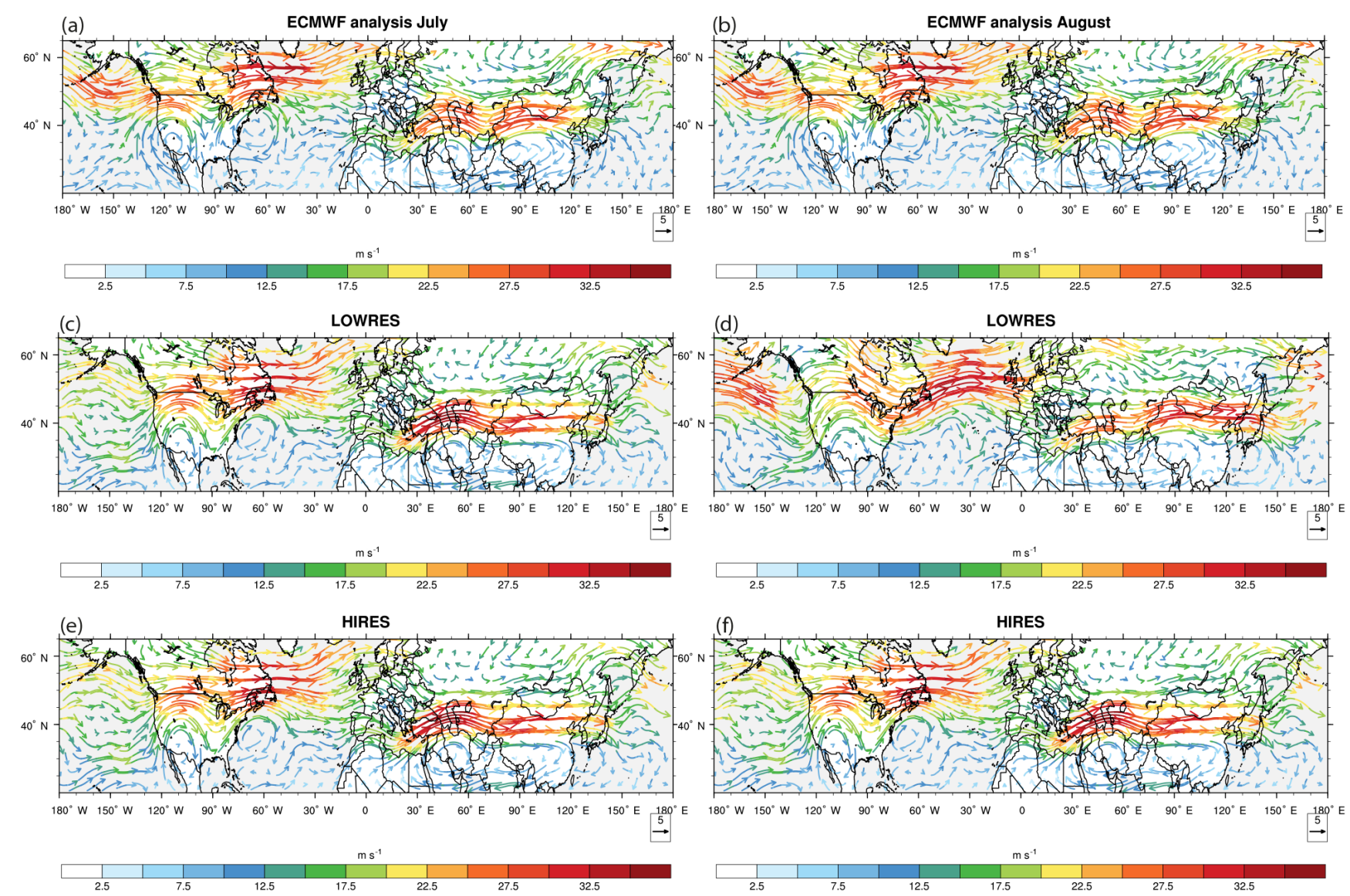

Figure 8. Mean $300 \mathrm{hPa}$ wind velocities for July 2013 (a, c, e) and August 2013 (b, d, f). The top row shows the ECMWF analysis, the middle row shows the LOWRES simulation, and the bottom row displays the HIRES simulation.

\subsection{Surface fields}

Figure 13 shows the mean $2 \mathrm{~m}$ temperature for the 12:00 UTC time steps. The LOWRES simulation shows hardly any bias over the western half of the model domain during July 2013, while the bias considerably grows in August 2013. The HIRES simulation (lower row of Fig. 13) shows hardly any bias over the ocean except over the Mediterranean where the model exhibits a cold bias of $\sim 1-$ $2 \mathrm{~K}$. In August, both WRF simulations show a similar temperature bias, as the pressure gradient on the east coast is very similar.

The $2 \mathrm{~m}$ temperatures over the Tarim Basin north of the Tibetan Plateau are significantly overestimated as shown in Fig. 13c-f. The simulated skin temperatures (TSKs) of both WRF simulations are $\sim 6 \mathrm{~K}$ higher than in the ECMWF analysis. As the $2 \mathrm{~m}$ temperatures are calculated based on the TSK and the second lowest model level, this leads to higher values. In addition, the warm bias over Africa during daytime turns into a cold bias during nighttime (not shown).

The $10 \mathrm{~m}$ wind speeds show a weak bias over the continents (Fig. 14) while larger deviations occur over the ocean due to the different locations of the low- and high-pressure systems. Especially in the west Pacific, the LOWRES simulation shows a large bias of about $5 \mathrm{~m} \mathrm{~s}^{-1}$ during both months, while the HIRES simulation is closer to the ECMWF analysis. The deviations in the Atlantic are the results of the slightly larger extent of the high-pressure system (see Fig. 5).

\subsection{Precipitation}

The upper panel of Fig. 15 shows the CMORPH accumulated precipitation for the 2-month period over land. Precipitation in most regions is between 50 and $300 \mathrm{~mm}$ for the 2 months. The precipitation peaks in the summer monsoon dominated southeast Asia and India. The precipitation in the southern United States is dominated by moist air mass inflow from the Gulf of Mexico in August 2013 (see Fig. 11). Overall, precipitation amounts are overestimated in both WRF simulations (Fig. 15b, c), apart from the western part of the United States.

The LOWRES simulation (Fig. 15b) shows an even stronger overestimation of precipitation in this regions related to the required convection parameterization which is responsible for over $90 \%$ of the total precipitation. It also 

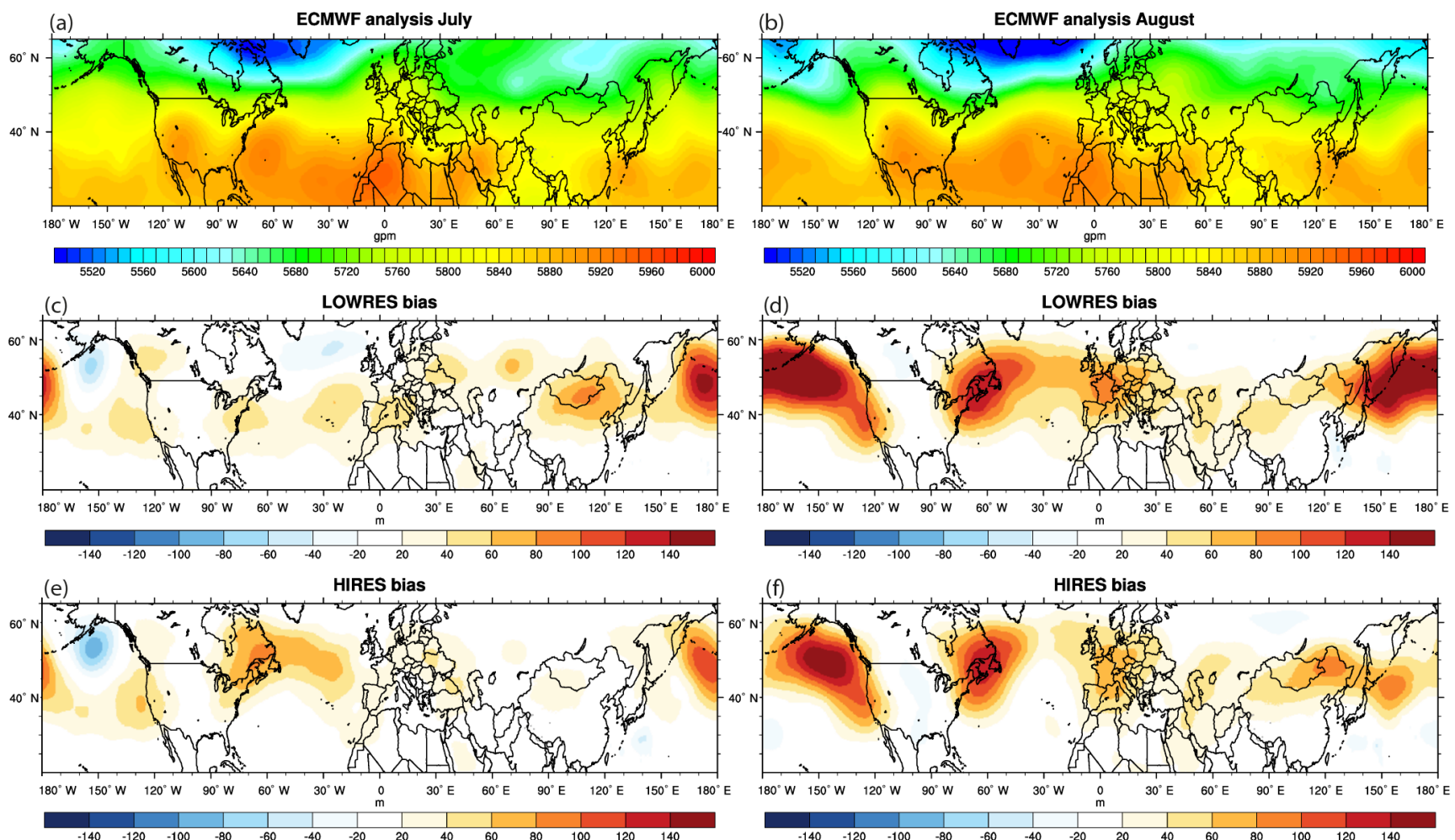

Figure 9. Mean $500 \mathrm{hPa}$ geopotential height and mean differences between the WRF simulations and ECMWF analysis at the 12:00 UTC time steps for July 2013 (a, c, e) and August 2013 (b, d, f). The top row shows the ECMWF analysis, the middle row shows the LOWRES simulation, and the bottom row displays the HIRES simulations.

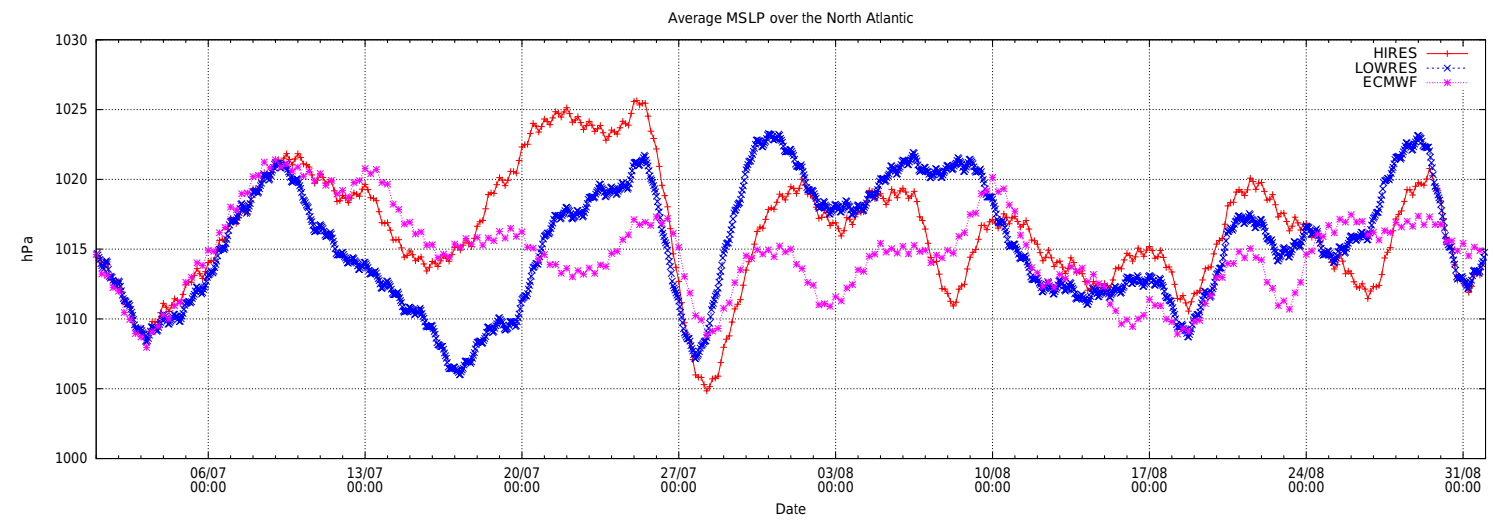

Figure 10. Time series of the MSLP averaged between 40 and $65^{\circ} \mathrm{N}$, and $60^{\circ} \mathrm{W}$ and $10^{\circ} \mathrm{E}$.

shows a tendency to simulate more widespread precipitation of lower intensities (Schwitalla et al., 2008).

The precipitation maximum over the Korean Peninsula caused by the East Asian monsoon and the maximum over Mexico due to the North American monsoon are also captured in the HIRES experiment. For the whole model domain, the mean estimated precipitation from CMORPH during the 2-month period is $137 \mathrm{~mm}$; the HIRES experiment simulates $186 \mathrm{~mm}$; the LOWRES experiment predicts $219 \mathrm{~mm}$ within the 2 months. The variance in both simulations is no- tably higher than given by the CMORPH analysis $(161 \mathrm{~mm})$ and the RMSE is $188 \mathrm{~mm}$ for the HIRES simulation and $207 \mathrm{~mm}$ for the LOWRES experiment. The average precipitation amount from the operational ECMWF forecasting system (Fig. 15d) is similar to the LOWRES simulation, although the average of $186 \mathrm{~mm}$ is closer to the HIRES simulation.

Although both WRF simulations show a positive precipitation bias, it is seen from Fig. 16 that the shape of the precipitation distribution is better represented in the HIRES simu- 
(a) ECMWF analysis
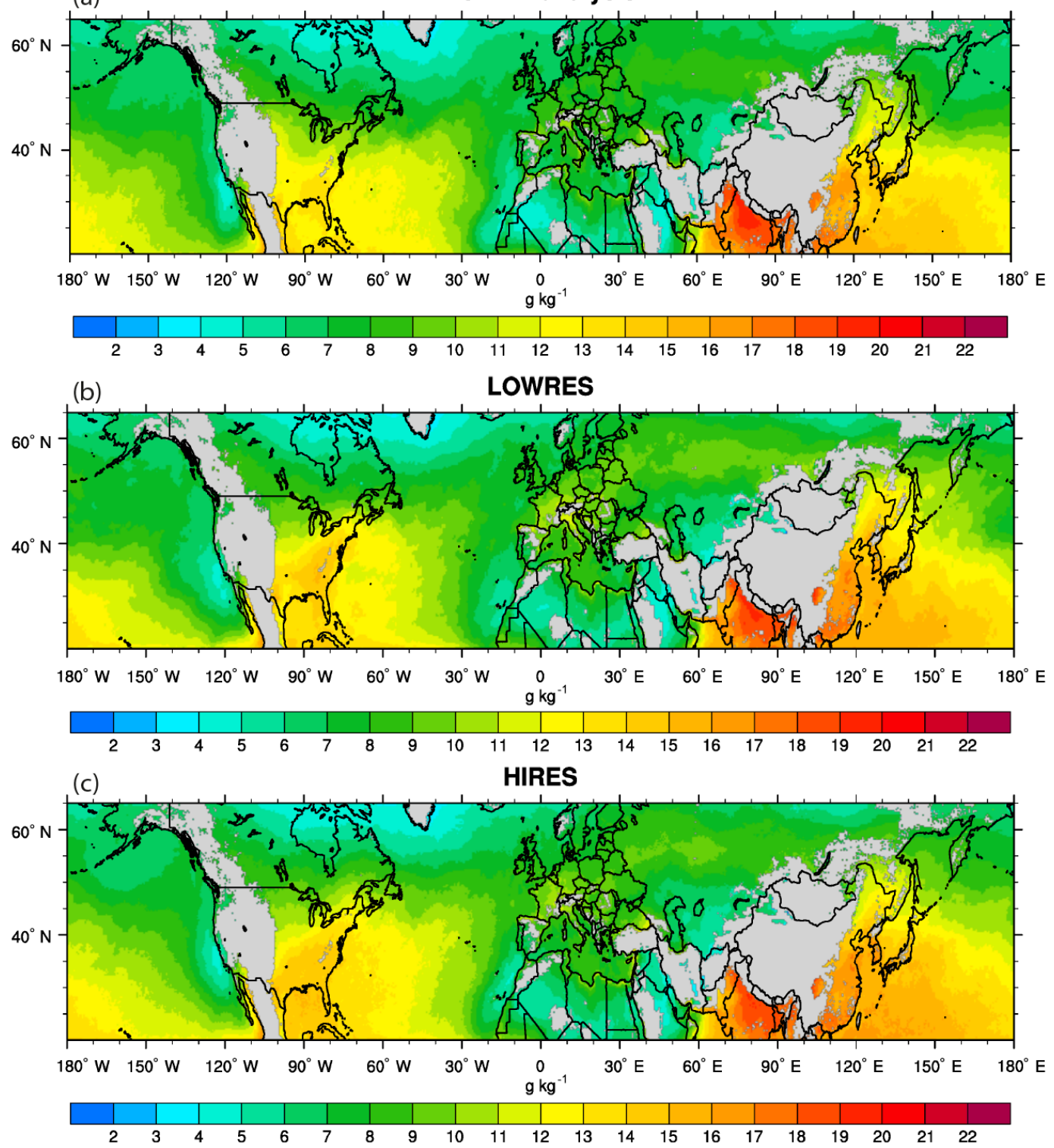

Figure 11. Average $925 \mathrm{hPa}$ water vapor mixing ratio for 12:00 UTC of the ECMWF analysis (a) and the LOWRES simulation (b). The bottom panel shows the HIRES simulation.

lation. In particular, the secondary peak in the precipitation amount of $100 \mathrm{~mm}$ is not visible in the LOWRES simulation. The positive benefit of the high resolution is also seen in the scatter plot displayed in Fig. 17. The regression line shows a systematic bias of $\sim 70-80 \mathrm{~mm}$ in both simulations; however, the LOWRES regression line has a different slope pointing to an increasing bias with increasing precipitation intensities which is a typical systematic error when applying a convection parameterization (Schwitalla et al., 2008).

As also central Europe, together with the Alpine region and the Spanish dry region, is of interest in terms of natural disasters caused by droughts and heavy precipitation (e.g., Gobiet et al., 2014), Fig. 18 displays the accumulated pre- cipitation over Europe for the 2-month period. The E-OBS analysis shows high precipitation amounts induced by orography over southwestern Norway, the central United Kingdom, and the Alps with values higher than $175 \mathrm{~mm}$. The low precipitation amount over the Iberian Peninsula with values lower than $20 \mathrm{~mm}$ is clearly visible and well simulated by the HIRES experiment. Compared to the mean precipitation of $87.7 \mathrm{~mm}$, the LOWRES simulation overestimates the total precipitation over Europe by $55 \%$, while the HIRES simulation only shows an overestimation of $25 \%$ in this region. In particular, the low precipitation amounts over Spain and Sweden are much better represented than in the LOWRES simulation (Fig. 18b). The PSS during the 2-month period 
(a) ECMWF analysis
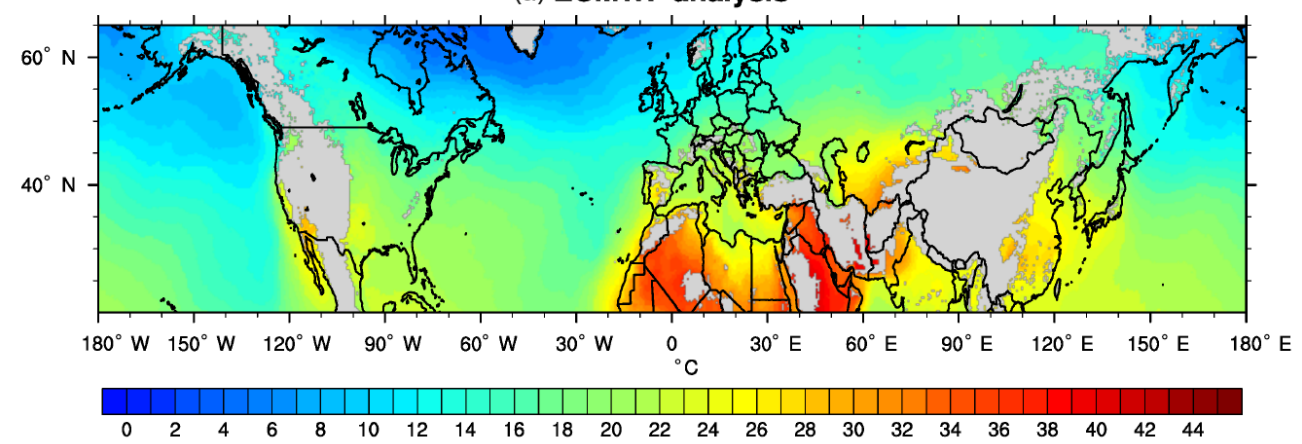

(b) LOWRES bias

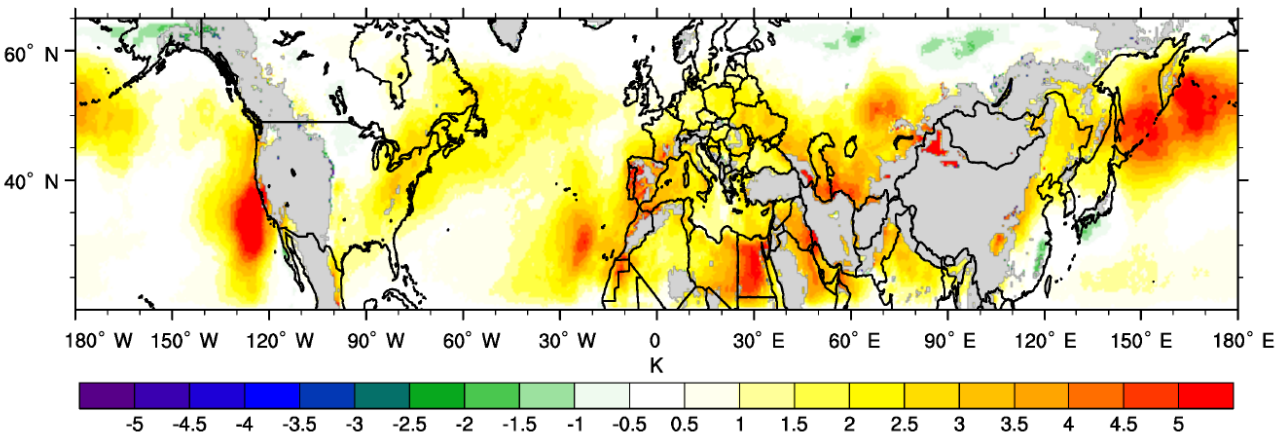

(c) HIRES bias

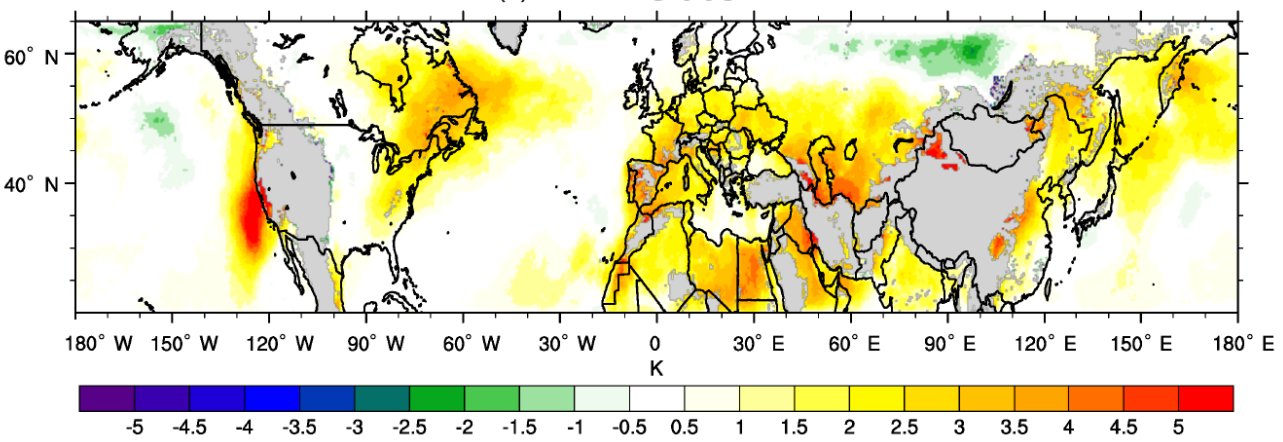

Figure 12. Mean $925 \mathrm{hPa}$ temperature for 12:00 UTC of the ECMWF analysis (a). Panels (b) and (c) show the deviation of the LOWRES and HIRES simulations from the ECMWF analysis, respectively.

yields a value of 0.75 for the LOWRES simulation and a value of 0.84 for the HIRES simulation. For a qualitative comparison, the ECMWF precipitation forecast is shown in addition (Fig. 18d).

The precipitation over the Alps is considerably overestimated by almost $100 \%$ and also the precipitation amounts over Spain are too high due to the application of a cumulus scheme. In addition, the overestimation due to an inaccurate representation of the terrain is clearly visible in the United Kingdom and southern Scandinavia. Compared to the observation and the HIRES simulation, the LOWRES experiment does not simulate the rain shadow area over Sweden. Although both WRF simulations show a positive bias, the precipitation distribution is much better represented by the HIRES simulation (Fig. 19).
Summarizing the statistical results, Fig. 20 shows a Taylor diagram for the spatial distribution of precipitation. The different verification regions are marked by the white rectangles shown in Fig. 1. This Taylor diagram combines information about the spatial correlation (azimuth angle) with the normalized centered RMSE (blue circles) and normalized standard deviation (dashed black circles). A perfect model would be at the point marked REF.

On the global scale, over Europe and east Asia, an indication for applying a CP resolution is given by the lower RMSE and standard deviations. Over central Asia and North America, the benefit is not as clear, as the correlation of the LOWRES simulation is better and the bias is not reduced by the higher resolution. Over Africa, the correlation is almost 
(a) ECMWF analysis July

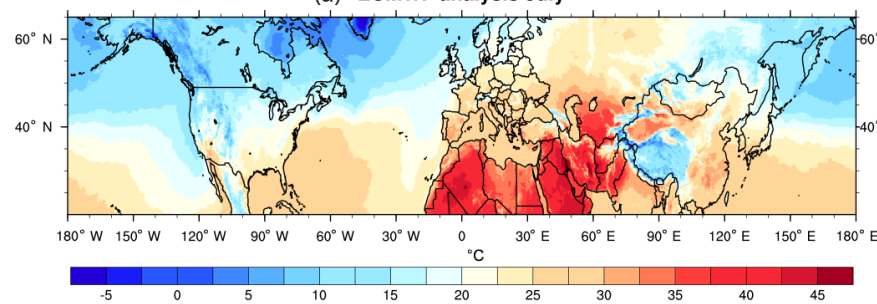

(c) LOWRES bias

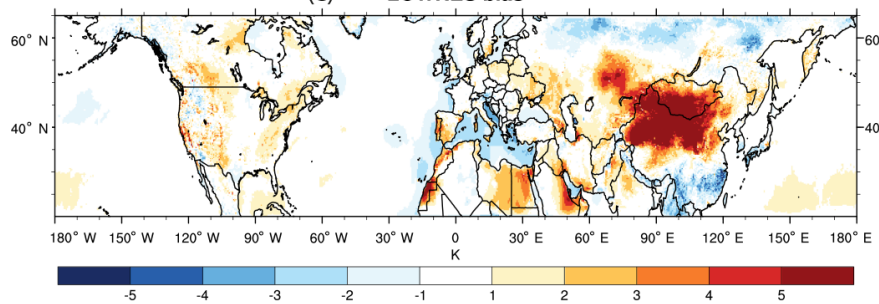

(e) HIRES bias

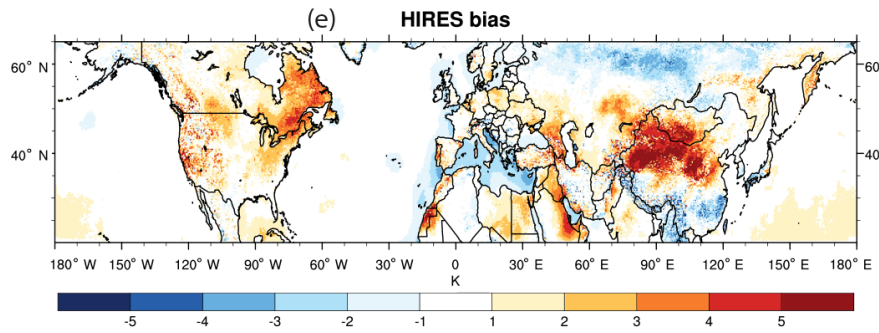

(b)ECMWF analysis August

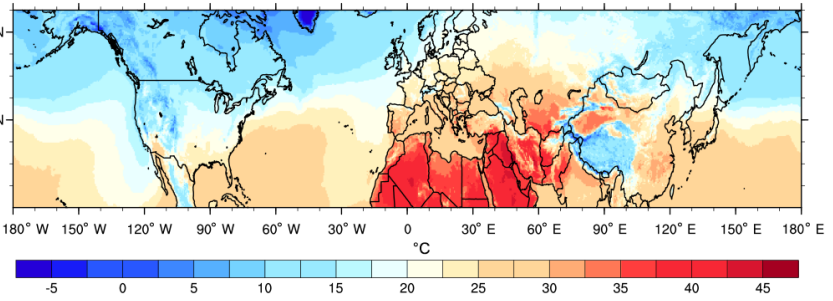

(d) LOWRES bias

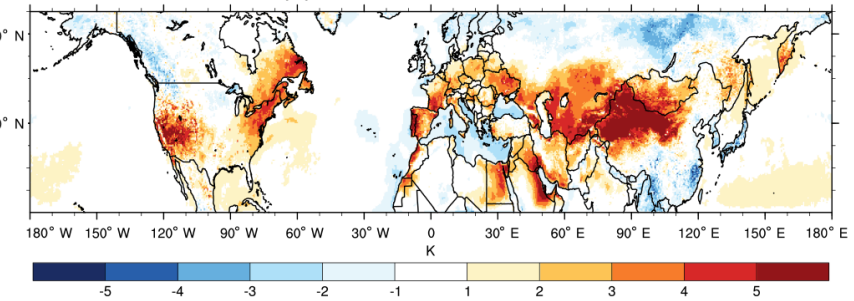

(f) HIRES bias

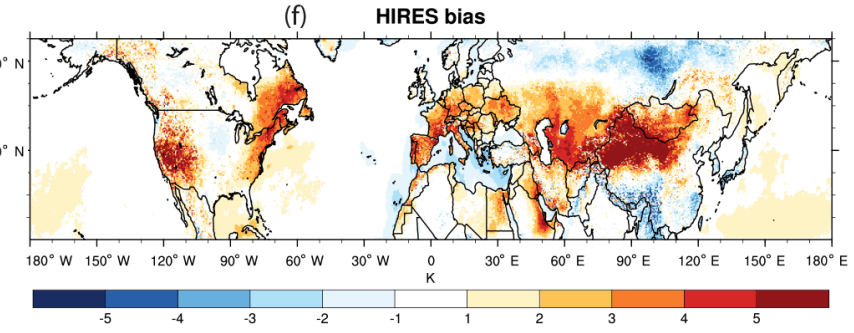

Figure 13. Mean $2 \mathrm{~m}$ temperature at 12:00 UTC in July (a, c, e) and August (b, d, f). The top row shows the ECMWF analysis, the middle row displays the LOWRES simulation, and the bottom row represents the HIRES simulation. Reddish colors indicate a warm bias of the WRF simulations.

(a) LOWRES bias

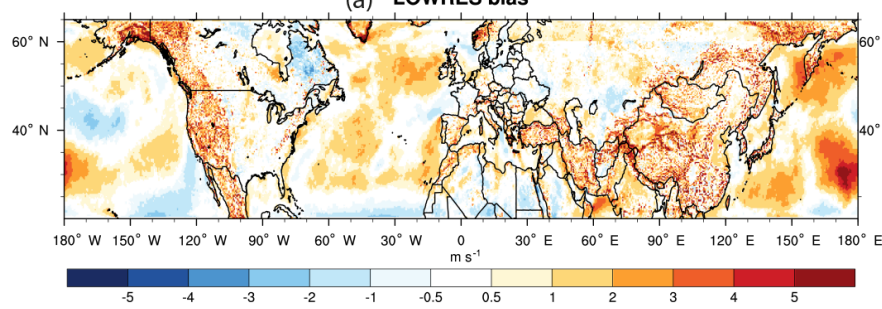

(c) HIRES bias

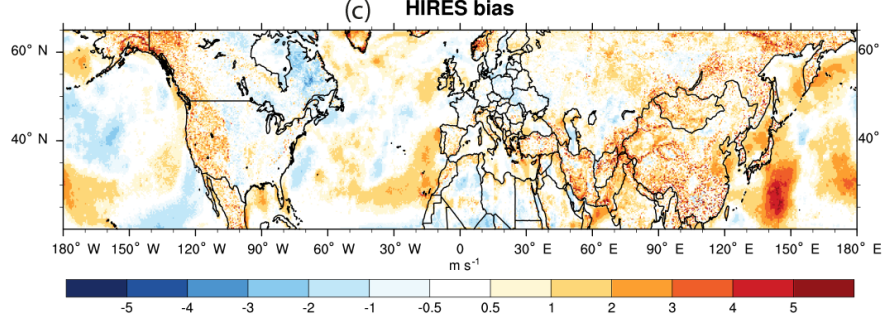

(b) LOWRES bias

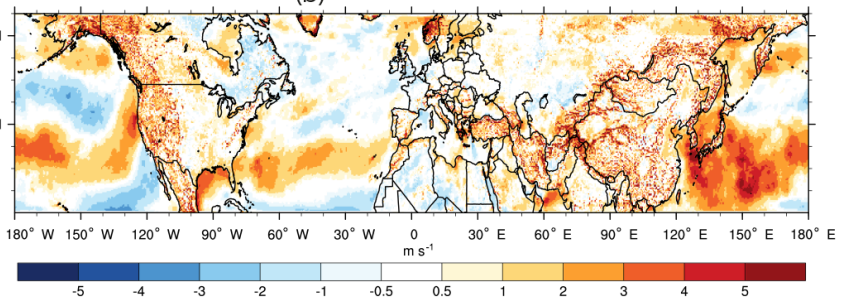

(d) HIRES bias

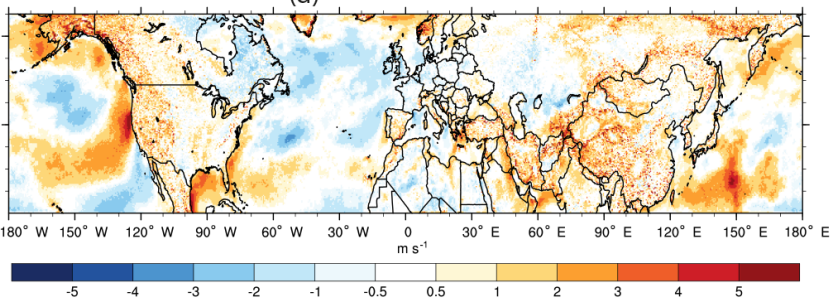

Figure 14. The $10 \mathrm{~m}$ wind speed bias in July (a, c) and August $2013(\mathbf{b}, \mathbf{d})$ for the LOWRES simulation (a, b) and the HIRES simulation (c, d).

similar but the HIRES simulation tends to slightly underestimate the amount of precipitation.

\section{Discussion}

The results from Sect. 4 indicate that both simulations show deficiencies in the representation of the large-scale and precipitation patterns. However, the convection-permitting res- 

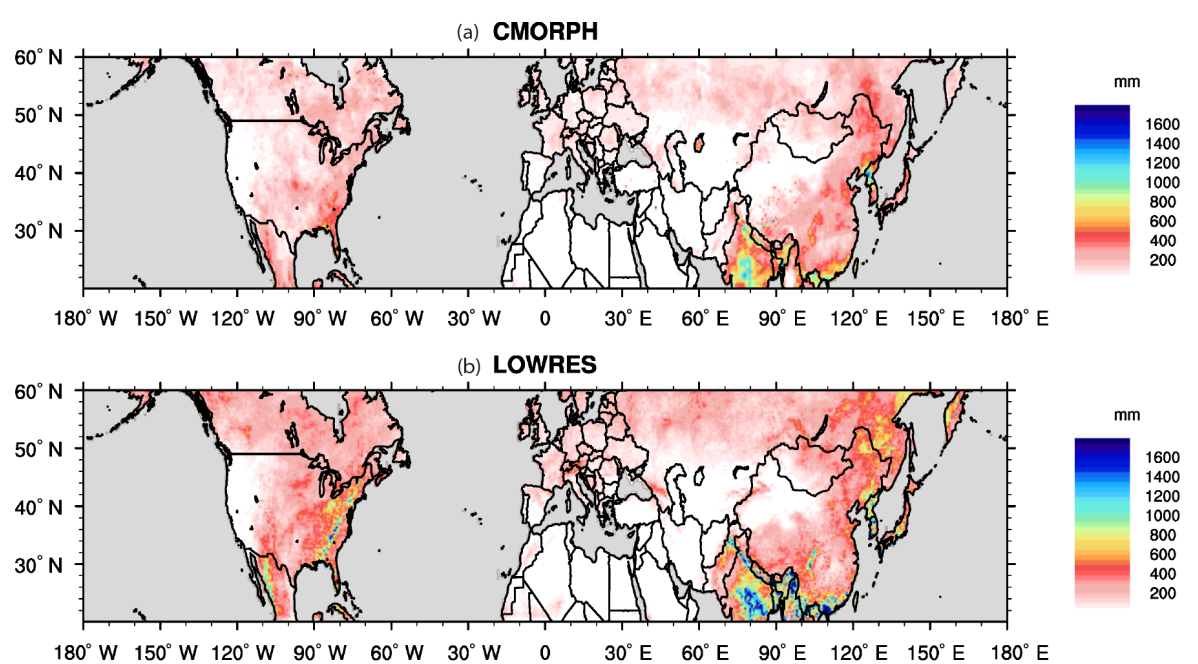

(c) HIRES

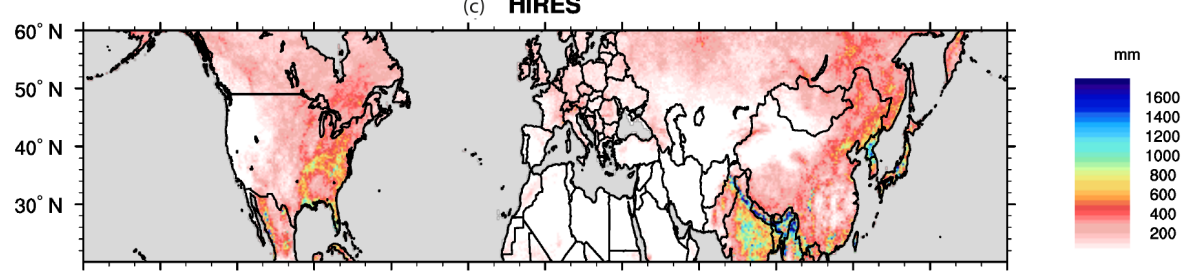

$180^{\circ} \mathrm{W} 150^{\circ} \mathrm{W} 120^{\circ} \mathrm{W} \quad 90^{\circ} \mathrm{W} \quad 60^{\circ} \mathrm{W} \quad 30^{\circ} \mathrm{W} \quad 0 \quad 30^{\circ} \mathrm{E} \quad 60^{\circ} \mathrm{E} \quad 90^{\circ} \mathrm{E} \quad 120^{\circ} \mathrm{E} \quad 150^{\circ} \mathrm{E} \quad 180^{\circ} \mathrm{E}$

(d) ECMWF

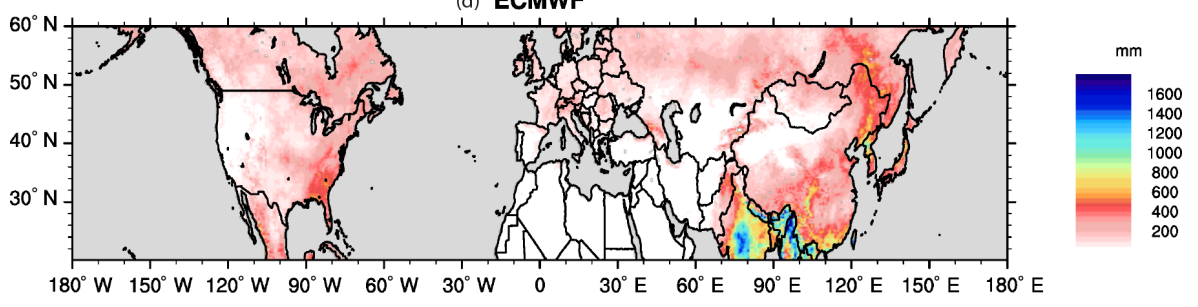

Figure 15. The 2-month accumulated precipitation. Panel (a) shows the CMORPH analysis, (b) shows the LOWRES simulation, and (c) displays the HIRES simulation. Panel (d) displays the accumulated precipitation from the operational ECMWF 12 h forecast starting at 00:00 and 12:00 UTC on each day.

olution helps to reduce biases associated with a reduction of the RMSE.

Especially over the northern Pacific, the lower-resolution simulation shows major deficiencies with an over-strong subtropical Pacific high showing a MSLP bias of more than $5 \mathrm{hPa}$. As the simulations are mainly driven by highresolution SST data and no zonal lateral boundaries are applied, the reasons can be traced back to the applied model configurations. The Pacific and North Atlantic are the most sensitive areas with respect to the development of storms (Fig. 7a, b); thus, small differences in temperatures due to the applied model physics can lead to different spatial and temporal evolutions of storm systems.

At coarser model resolutions, a strong MSLP bias of more than $10 \mathrm{hPa}$ was also observed in a study of Cassano et al. (2011) and is significantly reduced when a higher horizontal resolution is applied. Studies of Pai Mazumder et al. (2012) over Siberia and Efstathiou et al. (2013) over Greece also observed a tendency to overestimate the intensity of high and low-pressure systems when applying the YSU PBL scheme.

The variability of the MSLP over the western Pacific is considerably overestimated by both WRF experiments. The LOWRES experiment seems to have an even higher tendency to develop tropical storms as seen by the simulated corridor of higher standard deviation. The very high standard deviation over the Aleutian Islands may be related to the higher resolution, as these islands consist of volcanoes with elevations up to $2000 \mathrm{~m}$. As they are only partially resolved in the ECMWF model and especially with its 4D-Var system running at an even coarser resolution, this can explain the different behavior in this region. In combination with higherresolution SSTs and a better-represented land mask, this also contributes to higher sensitivities. 
(a) LOWRES

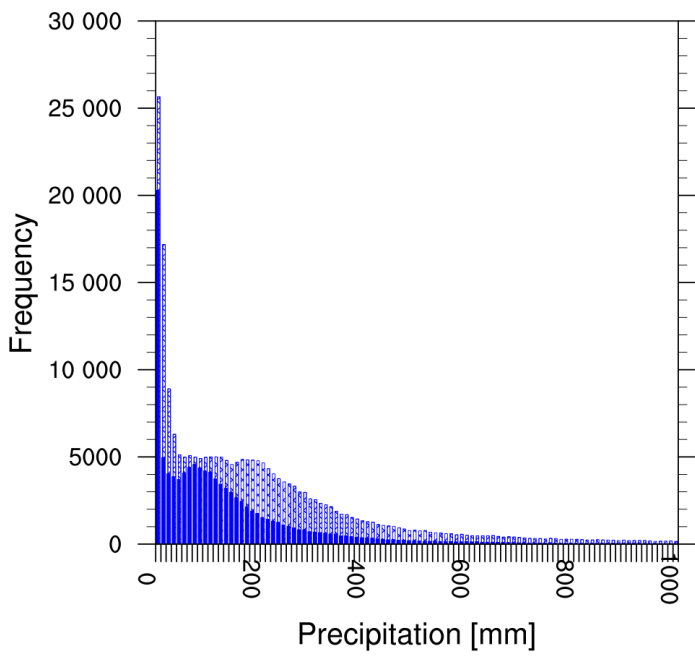

(b) HIRES

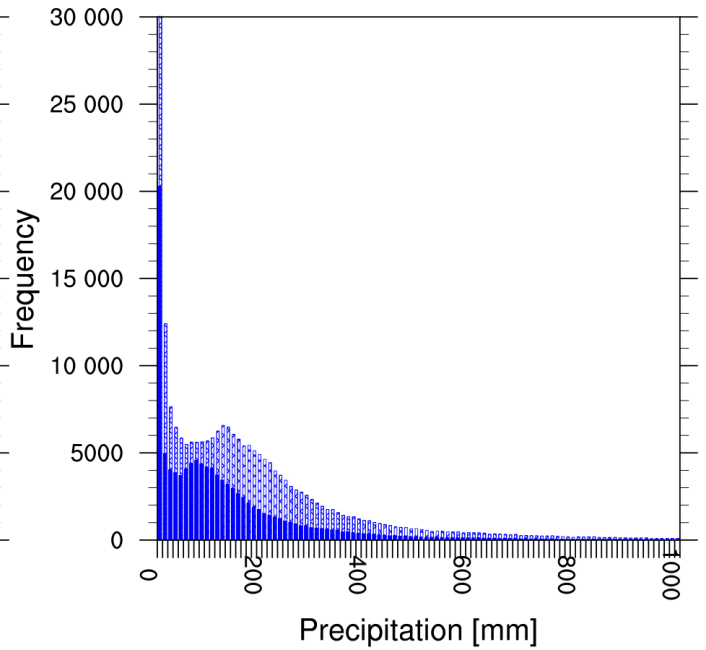

Figure 16. Histogram of the 2-month accumulated precipitation by using the CMORPH data over land points only. The filled blue bars denote the CMORPH data set and the cross-hatched bars denote the LOWRES (a) and HIRES simulation data (b).

(a) LOWRES vs. CMORPH

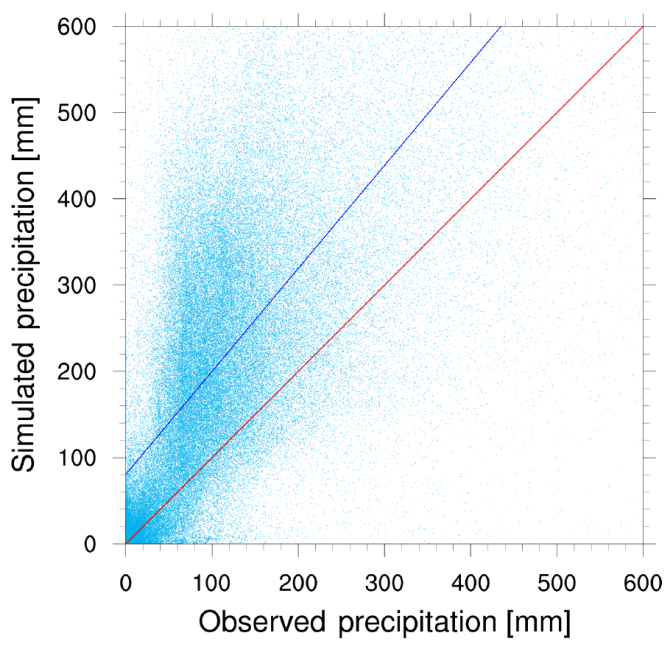

(b) HIRES vs. CMORPH

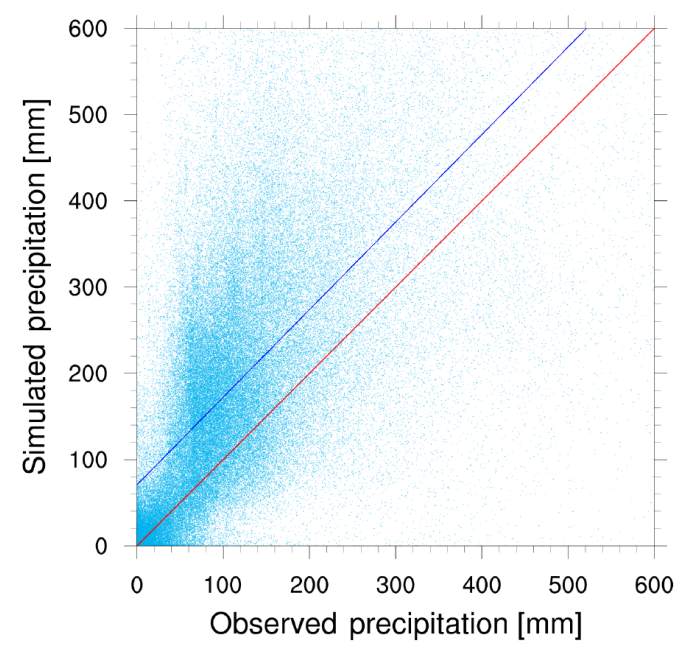

Figure 17. Scatter plot of the accumulated precipitation over the 2-month period including regression lines. The left panel shows the LOWRES simulation versus the CMORPH data. The red line indicates the perfect result. The right panel shows the HIRES simulation versus the CMORPH data.

Although the strong pressure and geopotential height bias over the east Pacific exist in both simulations, Fig. 6 gives an indication that, on longer timescales, the $\mathrm{CP}$ resolution has a beneficial impact on the simulation of the large-scale patterns. The bias expressed in terms of ECMWF standard deviations is considerably smaller the longer the forecast period is.

As the LOWRES simulation shows a totally different large-scale pattern in July 2013 compared to the HIRES simulation, the question arises whether the strong negative pressure bias over the North Atlantic simulation is caused by the combination of the applied physics scheme at this particular resolution.

A study of Kotlarski et al. (2014) revealed a similar result when comparing the large-scale circulation during the summer months, averaged over a 20-year period with the same physics combination as the LOWRES simulation using a common LAM approach. If a different microphysics scheme as, e.g., the WSM6 (Hong and Lim, 2006) is applied, the strong sea level pressure bias is not present anymore as seen in the CRP-GL configuration in Kotlarski et al. (2014). As the strong negative pressure bias is not visible in the HIRES simulation, this indicates an unfavorable combi- 

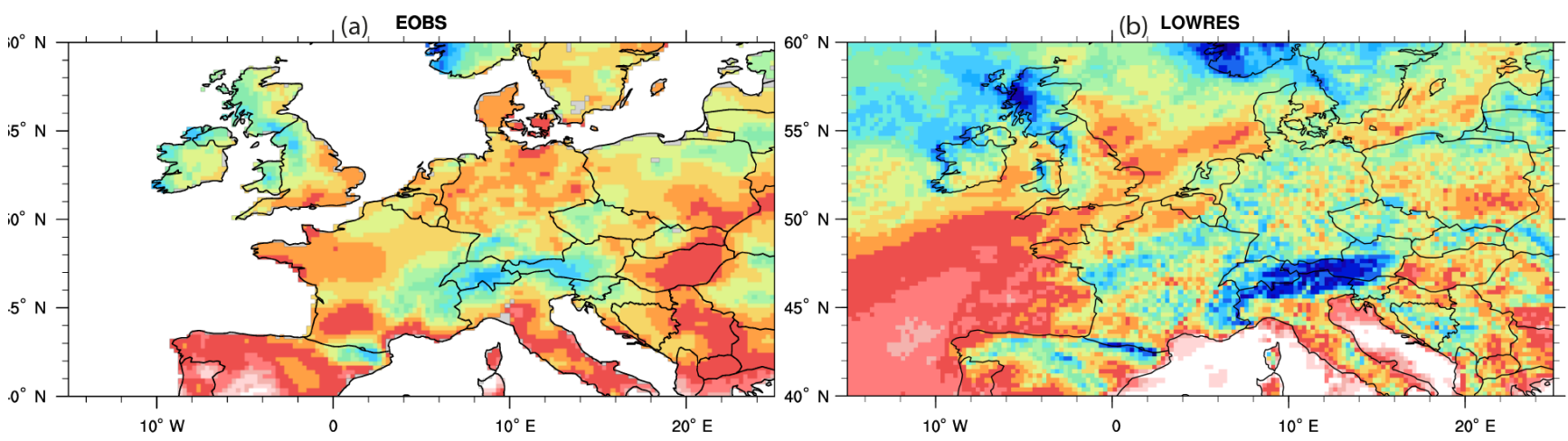

$\mathrm{mm}$
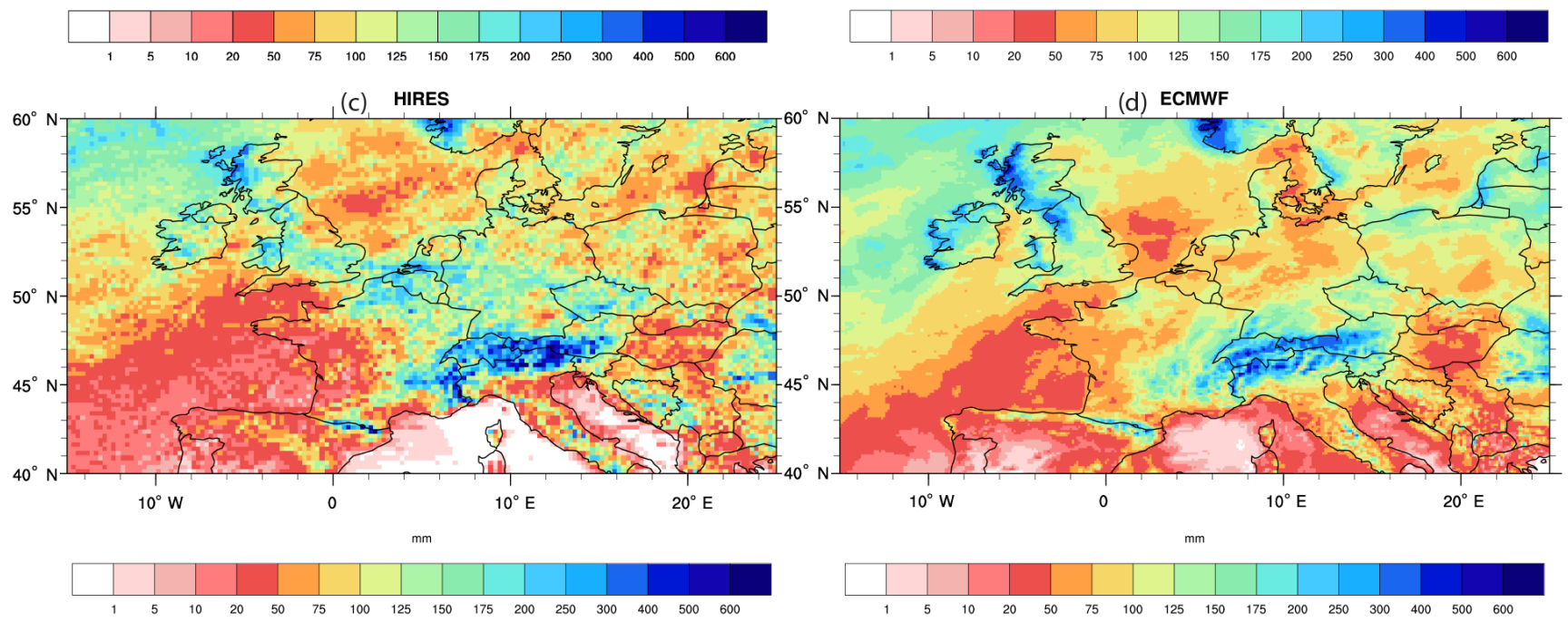

Figure 18. The 2-month accumulated precipitation over Europe. Panel (a) shows the E-OBS data set, (b) shows the LOWRES simulation, (c) displays the HIRES simulation, and (d) shows the ECMWF forecast.

(a) LOWRES

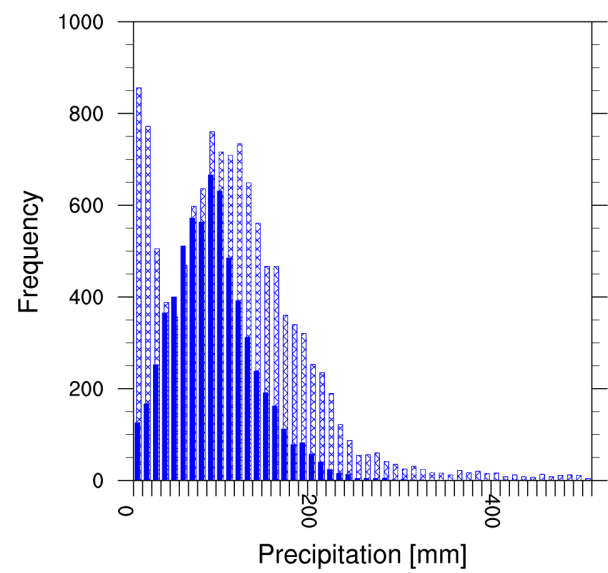

(b) HIRES

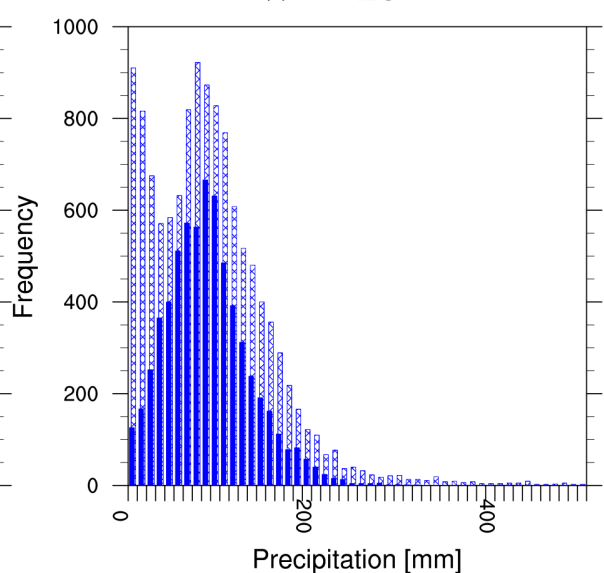

Figure 19. Histogram of the 2-month accumulated precipitation over Europe using the E-OBS data set. The filled blue bars denote the observation data set and the cross-hatched bars denote the HIRES (a) and LOWRES (b) simulation data.

nation of the Kain-Fritsch convection parameterization with the Morrison microphysics scheme with the coarser resolution over the subpolar regions.
The Morrison scheme uses a fixed cloud droplet concentration of $250 \mathrm{~cm}^{-3}$. This concentration is adjusted at every model time step and is set to this constant value at the 


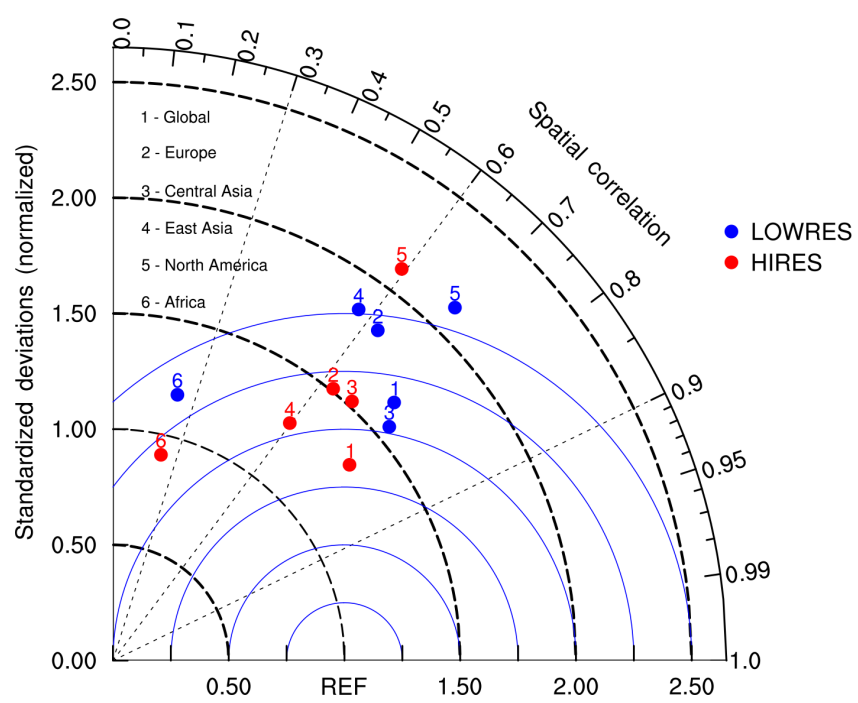

Figure 20. Taylor diagram of the accumulated precipitation over land points. The simulations were plotted against CMORPH observations, except for Europe where the E-OBS data set is the reference.

end of a vertical loop. The ice nucleation follows a formula of Rasmussen et al. (2002) which is primarily designed for midlatitudes. WRF offers another switch based on observations from the Arctic but this is an on-off switch for the whole model domain. In particular, the fixed particle concentration can lead to a more intense formation of optically thick clouds reducing the solar irradiation. For example, in the Polar-WRF model (Bromwich et al., 2013), the cloud droplet concentration is reduced to $50 \mathrm{~cm}^{-3}$ to produce fewer liquid water droplets.

The different location of the polar jet over the North Atlantic can result in the transport of warmer and moist air masses from the central Atlantic towards the north. This can enhance convection over the Atlantic having a strong influence on the simulation of precipitation over Europe. It also intensifies the cyclogenesis which can lead to more severe storms over Europe and also more precipitation over the eastern part of the United States.

Cassano et al. (2011) performed a simulation in which they exchanged the default Goddard microphysics scheme (Tao and Simpson, 1993) with the Morrison two-moment scheme combined with the Grell-Dévényi convection parameterization (Grell and Dévényi, 2002). The precipitation bias over the Arctic was increased by about $50 \%$ by applying this physics combination. Therefore, it may be necessary to either adjust these parameters according to the latitude when performing simulations in subpolar regions or to apply a different combination of cloud microphysics and convection parameterizations at coarser grid resolutions.

Referring to Fig. 10, the potential influence of the northern boundaries was investigated by slightly varying the domain. When selecting a much smaller domain between 60 $10^{\circ} \mathrm{W}$ and $40-55^{\circ} \mathrm{N}$, the curve progression of the MSLP and $500 \mathrm{hPa}$ geopotential height is very similar to the behavior shown in Fig. 10 (not shown here). This indicates that the influence of the northern boundaries on the development of the simulation compared to the SST is not significant, especially as the meridional wind speed is very weak in this area.

The general appearance of the boundary layer humidity fields is comparable with the ECMWF analysis but both simulations show a positive water vapor bias of 0.6 (HIRES) and $0.4 \mathrm{~g} \mathrm{~kg}^{-1}$ (LOWRES) during the 2-month period. This is associated with a temperature bias up to the middle troposphere over the west coast of the US, east Canada, and Inner Mongolia.

In the regions where the $2 \mathrm{~m}$ temperature bias is very large (the west coast of the US, east Canada, Mongolia, Inner Mongolia, and the Xinjiang region), the background albedo used in the WRF simulations is $\sim 5-10 \%$ lower compared to the ECMWF albedo, leading to higher absorption of radiation by the surface resulting in higher surface and soil temperatures (e.g., Branch et al., 2014). The main difference between both albedo data sets is that the ECMWF model has a climatological, fixed albedo throughout the year while the albedo used in the WRF simulations is time varying. Another source for the differences is that the ECMWF 4D-Var analysis requires a forecast model with different physics schemes compared to the WRF model. In the case of a low observation density, this could also contribute to the differences.

As pointed out by Zhang et al. (2014), the soil hydraulic parameters used in the NOAH LSM show some deficiencies in desert and steppe regions over Inner Mongolia. As our study makes use of an improved version of the thermal roughness length calculation over land (Chen and Zhang, 2009), it appears that a more proper description of the canopy resistance over the desert steppe can be beneficial. At present, the WRF model system unfortunately does not offer the possibility of latitude- or region-varying parameters for the land-surface models.

A major advantage of the HIRES simulation is that the precipitation distribution is much better represented compared to the LOWRES simulation. This is especially true for Europe where the simulations were verified against EOBS data. Here, the HIRES simulation is much closer to the observed precipitation distribution, although it also tends to produce spurious precipitation amounts. A reason for the overestimation of precipitation over Asia in the LOWRES simulation is the higher wind speeds at $10 \mathrm{~m}$ over eastern China and the Pacific (Fig. 14), leading to higher evaporation and thus a higher moisture availability (see also Fig. 11). Together with the applied convection parameterization, this can enhance the precipitation amounts considerably. In addition, the LOWRES simulation shows a similar overestimation of precipitation over India, Bangladesh, and Myanmar compared to the ECMWF operational model. This is not a big surprise as both models use a convection parameterization although the applied schemes differ. 
Over central Asia, the benefit of the $\mathrm{CP}$ resolution is not clearly visible. This can be related to possible weaknesses in the CMORPH analysis over very complex terrain, even when corrected with in situ observations (e.g., Gebremichael et al., 2014; Skok et al., 2016). Another factor influencing the Indian monsoon can be the role of aerosols, but this is beyond the scope of this study. Over North America, the HIRES simulation shows a slightly worse correlation compared to the LOWRES experiment due to an overestimation of precipitation over the eastern United States (Fig. 15b) which apparently can be connected to a moist inflow bias at $925 \mathrm{hPa}$ (Fig. 11b).

The overestimation of precipitation over the eastern part of the Unites States in both WRF simulations is related to the shift of the pressure system. This shift allows a moist inflow from the Atlantic and the Gulf of Mexico, leading to higher precipitation amounts which are not simulated by the operational ECMWF forecasts.

On the global scale, over Europe and east Asia, an indication for applying a $\mathrm{CP}$ resolution is given by the lower RMSE and standard deviations. Over central Asia and North America, the benefit is not as clear as the correlation of the LOWRES simulation is better and the bias is not reduced by the higher resolution. Here, a better-resolved terrain might deteriorate the situation with inaccurate soil hydraulic parameters. Over Africa, the correlation is almost similar but the HIRES simulation tends to slightly underestimate the amount of precipitation. Following Perkins et al. (2007) and Devis et al. (2013), the improved PSS clearly points towards the application of the $\mathrm{CP}$ resolution.

\section{Summary}

Two latitude-belt simulations with the WRF-ARW model between 20 and $65^{\circ} \mathrm{N}$ have been evaluated for July and August 2013. One simulation was performed at $0.12^{\circ}$ resolution typical for currently applied RCMs and the other simulation was performed on the convection-permitting scale with a resolution of $0.03^{\circ}$. Meridional boundaries were provided every $6 \mathrm{~h}$ by the ECMWF operational analysis. The lower boundary forcing is provided by daily high-resolution SST data from the OSTIA project interpolated to 6-hourly intervals.

Nevertheless, they are undisturbed by LBCs in the westeast direction as in commonly applied LAM applications and therefore allow for new insights into model resolution dependence of the results. Although northern and southern boundaries are applied, the results now depend on model physics and resolution only. Therefore, the results can be assessed with respect to the model performance itself rather than the domain size and inconsistencies of model physics at the zonal boundaries. This is important as, e.g., Eurasia and North America are characterized by the impact of the polar and subtropical jets and the sea surface temperatures of the
Atlantic and Pacific gyres, namely the Gulf Stream and the Kuroshio Current on the general atmospheric circulation.

The simulations were compared to ECMWF operational analyses data at $0.12^{\circ}$ resolution and to observational precipitation data sets of CMORPH and E-OBS at $0.25^{\circ}$ resolution, since harmonized precipitation data sets are not available at higher resolution. The objective of the study was to evaluate the performance and benefit of applying a convectionpermitting resolution when performing latitude-belt simulations over an extended forecast period.

A benefit of the higher model resolution can be seen in the pressure fields of both months in terms of a bias reduction. The spatial distribution between both WRF simulations do greatly differ over the Atlantic during the first month, while there is a considerable improvement at longer forecast periods at higher resolution over the Pacific, indicated by bias reduction and improvement of the PSS. The CP resolution also seems to be able to better capture the middle and upper tropospheric features, e.g., the location of the subpolar jet stream. Also, the temperature and moisture bias is slightly reduced in the lower troposphere although an average bias of $0.5 \mathrm{~g} \mathrm{~kg}^{-3}$ and $1.5 \mathrm{~K}$ still remains.

Over land, both simulations show the same biases in the $2 \mathrm{~m}$ temperature and $10 \mathrm{~m}$ wind speeds. This indicates that the biases are subject to the physical parameterization schemes of WRF, namely those describing the subgrid-scale land-atmosphere feedback processes and are inferior to the applied resolution.

The CP resolution shows an enhancement concerning the precipitation amount in the whole domain except North America, where LOWRES compares better with the studied precipitation data sets. Over Europe, the CP resolution results in an improved distribution of precipitation amounts indicated by a higher PSS and considerably lower bias and RMSE. Concerning the spatial correlation, there is no clear signal for a major improvement of the higher resolution but one has to bear in mind the rather coarse resolution of the precipitation data sets.

This study also showed that the physical parameterizations need to be assessed to provide more accurate simulations of the climate and also to provide less biased surface variables to the impact models as required by the society. Namely the land-atmosphere feedback and interactions need to be investigated in a synergy of novel high-resolution observational data (e.g., from the Surface Atmosphere Boundary Layer Exchange experiment - SABLE; Wulfmeyer and Coauthors, 2015) seamless model applications down to LES, and new evaluation techniques (e.g., Wulfmeyer et al., 2016) to improve the physical parameterization schemes on the applied model resolution.

As computing resources are continuously growing, the potential for an increase of the simulation period for such $\mathrm{CP}$ latitude-belt simulations is given. 
Code availability. To download the WRF source code, users need to register on the following website: http://www2.mmm.ucar.edu/ wrf/users/download/wrf-regist.php. Apart from the default required NetCDF and MPI libraries, users need to install the PnetCDF libraries version 1.5.0 or higher from the Argonne National Laboratory (https://trac.mcs.anl.gov/projects/parallel-netcdf).

\section{The Supplement related to this article is available online at doi:10.5194/gmd-10-2031-2017-supplement.}

Author contributions. The experiment including setting up the simulations and modifying the code was carried out by T. Schwitalla. The analysis of the simulations was performed in a collaborative effort and the paper was prepared by T. Schwitalla with contributions by all co-authors.

Acknowledgements. We are grateful to the High Performance Computing Center Stuttgart (HLRS) and to Cray Inc. for providing the tremendous amount of computing time required for this simulation on the XC40 system. We give special thanks to U. Küster, T. Beisel, and T. Bönisch from HLRS, and to S. Andersson and S. Dieterich from Cray Inc. We are also grateful to the ECMWF for providing operational analysis data. We also thank the two anonymous referees for their valuable comments to improve the manuscript.

Edited by: S. Unterstrasser

Reviewed by: two anonymous referees

\section{References}

Acs, F., Horvath, A., Breuer, H., and Rubel, F.: Effect of soil hydraulic parameters on the local convective precipitation, Meteorol. Z., 19, 143-153, 2010.

Albergel, C., de Rosnay, P., Gruhier, C., Munoz Sabater, J., Hasenauer, S., Isaksen, L., Kerr, Y., and Wagner, W.: Evaluation of remotely sensed and modelled soil moisture products using global ground-based in situ observations, Remote Sens. Environ., 118, 215-226, doi:10.1016/j.rse.2011.11.017, 2012.

Balsamo, G., Viterbo, P., Beljaars, A., van den Hurk, B., Hirschi, M., Betts, A., and Scipal, K.: A Revised Hydrology for the ECMWF Model: Verification from Field Site to Terrestrial Water Storage and Impact in the Integrated Forecast System, J. Hydrometeorol., 10, 623-641, 2009.

Bauer, H.-S., Weusthoff, T., Dorninger, M., Wulfmeyer, V., Schwitalla, T., Gorgas, T., Arpagaus, M., and Warrach-Sagi, K.: Predictive skill of a subset of models participating in D-PHASE in the COPS region, Q. J. Roy. Meteorol. Soc., 137, 287-305, 2011.

Bauer, H.-S., Schwitalla, T., Wulfmeyer, V., Bakhshaii, A., Ehret, U., Neuper, M., and Caumont, O.: Quantitative precipitation estimation based on high-resolution numerical weather prediction and data assimilation with WRF - a performance test, Tellus A, 67, doi:10.3402/tellusa.v67.25047, 2015a.
Bauer, P., Thorpe, A., and Brunet, G.: The quiet revolution of numerical weather prediction, Nature, 525, 47-55, doi:10.1038/nature14956, 2015b.

Becker, N., Ulbrich, U., and Klein, R.: Systematic large-scale secondary circulations in a regional climate model, Geophys. Res. Lett., 42, 4142-4149, doi:10.1002/2015GL063955, 2015.

Branch, O., Warrach-Sagi, K., Wulfmeyer, V., and Cohen, S.: Simulation of semi-arid biomass plantations and irrigation using the WRF-NOAH model; a comparison with observations from Israel, Hydrol. Earth Syst. Sc., 18, 1761-1783, doi:10.5194/hess18-1761-2014, 2014.

Bromwich, D. H., Otieno, F. O., Hines, K. M., Manning, K. W., and Shilo, E.: Comprehensive evaluation of polar weather research and forecasting model performance in the Antarctic, J. Geophys. Res.-Atmos., 118, 274-292, doi:10.1029/2012JD018139, 2013.

Cassano, J. J., Higgins, M. E., and Seefeldt, M. W.: Performance of the Weather Research and Forecasting Model for Month-Long Pan-Arctic Simulations, Mon. Weather Rev., 139, 3649-3488, doi:10.1175/MWR-D-10-05065.1, 2011.

Chen, F. and Dudhia, J.: Coupling an advanced landsurface/hydrology model with the Penn State NCAR MM5 modeling system. Part I: Model implementation and sensitivity, Mon. Weather Rev., 129, 569-585, 2001.

Chen, F. and Zhang, Y.: On the coupling strength between the land surface and the atmosphere: From viewpoint of surface exchange coefficients, Geophys. Res. Lett., 36, L10404, doi:10.1029/2009GL037980, 2009.

Coppala, E., Giorgi, F., Mariotti, L., and Bi, X.: RegT-Band: a tropical band version of RegCM4, Clim. Res., 52, 115-133, 2012.

Dee, D. P., Uppala, S. M., Simmons, A. J., Berrisford, P., Poli, P., Kobayashi, S., Andrae, U., Balmaseda, M. A., Balsamo, G., Bauer, P., Bechtold, P., Beljaars, A. C. M., van de Berg, L., Bidlot, J., Bormann, N., Delsol, C., Dragani, R., Fuentes, M., Geer, A. J., Haimberger, L., Healy, S. B., Hersbach, H., Hólm, E. V., Isaksen, L., Kållberg, P., Köhler, M., Matricardi, M., McNally, A. P., Monge-Sanz, B. M., Morcrette, J.-J., Park, B.-K., Peubey, C., de Rosnay, P., Tavolato, C., Thépaut, J.-N., and Vitart, F.: The ERA-Interim reanalysis: configuration and performance of the data assimilation system, Q. J. Roy. Meteorol. Soc., 137, 553597, doi:10.1002/qj.828, 2011.

Devis, A., van Lipzig, N. P. M., and Demuzere, M.: A new statistical approach to downscale wind speed distributions at a site in northern Europe, J. Geophys. Res.-Atmos., 118, 2272-2283, doi:10.1002/jgrd.50245, 2013.

Diaconescu, E. P. and Laprise, R.: Can added value be expected in RCM-simulated large scales?, Clim. Dynam., 41, 1769-1800, doi:10.1007/s00382-012-1649-9, 2013.

Dong, B., Sutton, R., and Shaffrey, L.: The 2013, hot, dry, summer in western Europe, B. Am. Meteorol. Soc., 95, S62-S66, in "Explaining Extremes of 2013 from a Climate Perspective”, 2014.

Donlon, C. J., Martin, M., Stark, J., Roberts-Jones, J., Fiedler, E., and Wimmer, W.: The Operational Sea Surface Temperature and Sea Ice Analysis (OSTIA) system, Remote Sens. Environ., 116, 140-158, doi:10.1016/j.rse.2010.10.017, 2012.

Dudhia, J.: Reply to comment on "A nonhydrostatic version of the Penn State NCAR mesoscale model: Validation tests and simulations of an Atlantic cyclone and cold front" by J. Steppeler, Mon. Weather Rev., 123, 2573-2575, 1995. 
Efstathiou, G., Zoumakis, N., Melas, D., Lolis, C., and Kassomenos, P.: Sensitivity of $\{\mathrm{WRF}\}$ to boundary layer parameterizations in simulating a heavy rainfall event using different microphysical schemes. Effect on large-scale processes, Atmos. Res., 132-133, 125-143, doi:10.1016/j.atmosres.2013.05.004, 2013.

Ek, M. B., Mitchell, K. E., Lin, Y., Rogers, E., Grummann., P., Koren, V., Gayno, G., and Tarpley, J. D.: Implementation of NOAH land surface model advances in the National Centers for Environmental Prediction operational Mesoscale Eta Model, J. Geophys. Res., 108, D22, doi:10.1029/2002JD003296, 2003.

Evan, S., Rosenlof, K. H., Dudhia, J., Hassler, B., and Davis, S. M.: The representation of the TTL in a tropical channel version of the WRF model, J. Geophys. Res.-Atmos., 118, 2835-2848, doi:10.1002/jgrd.50288, 2013.

Fonseca, R. M., Zhang, T., and Yong, K.-T.: Improved simulation of precipitation in the tropics using a modified BMJ scheme in the WRF model, Geosci. Model Dev., 8, 2915-2928, doi:10.5194/gmd-8-2915-2015, 2015.

Gebremichael, M., Bitew, M. M., Hirpa, F. A., and Tesfay, G. N.: Accuracy of satellite rainfall estimates in the Blue Nile Basin: Lowland plain versus highland mountain, Water Resour. Res., 50, 8775-8790, doi:10.1002/2013WR014500, 2014.

Giorgi, F., Jones, C., and Asrar, G. R.: Addressing climate information needs at the regional level: the CORDEX framework, WMO Bull., 58, 2009.

Gobiet, A., Kotlarski, S., Beniston, M., Heinrich, G., Rajczak, J., and Stoffel, M.: 21st century climate change in the European Alps- A review, Sci. Total Environ., 493, 1138-1151, doi:10.1016/j.scitotenv.2013.07.050, 2014.

Grell, G. A. and Dévényi, D.: A generalized approach to parameterizing convection combining ensemble and data assimilation techniques, Geophys. Res. Lett., 29, 38-1-38-4, doi:10.1029/2002GL015311, 2002.

Grell, G. A., Dudhia, J., and Stauffer, R. R.: A description of the fifth-generation Penn State/NCAR mesoscale model (MM5), NCAR technical Note TN-398+STR, NCAR, Boulder/CO, 122 pp., 1995.

Haylock, M. R., Hofstra, N., Klein Tank, A. M. G., Klok, E. J., Jones, P. D., and New, M.: A European daily highresolution gridded data set of surface temperature and precipitation for 1950-2006, J. Geophys. Res.-Atmos., 113, doi:10.1029/2008JD010201, 2008.

Heikkilä, U., Sandvik, A., and Sorteberg, A.: Dynamical downscaling of ERA-40 in complex terrain using the WRF regional climate model, Clim. Dynam., 37, 1551-1564, doi:10.1007/s00382-010-0928-6, 2011.

Hong, S.-Y.: Stable Boundary Layer Mixing in a Vertical Diffusion Scheme, the Korea Meteor. Soc., Fall conference, Seoul, Korea, 25-26 October, 2007.

Hong, S. Y. and Lim, J.-O. J.: The WRF Single-Moment 6-Class Microphysics Scheme (WSM5), J. Korean Meteor. Soc., 42, 129-151, 2006

Hong, S.-Y., Park, H., Cheong, H.-B., Kim, J.-E., Koo, M.-S., Jang, J., Ham, S., Hwang, S.-O., Park, B.-K., Chang, E.-C., and Li, H.: The Global/Regional Integrated Model system (GRIMs), AsiaPac. J. Atmos. Sci., 49, 219-243, 2013.

Huffman, G. J., Bolvin, D. T., Nelkin, E. J., Wolff, D. B., Adler, R. F., Gu, G., Hong, Y., Bowman, K. P., and Stocker, E. F.: The TRMM Multisatellite Precipitation Analy- sis (TMPA): Quasi-Global, Multiyear, Combined-Sensor Precipitation Estimates at Fine Scales, J. Hydrometeorol., 8, 38-55, doi:10.1175/JHM560.1, 2007.

Iacono, M. J., Delamere, J. S., Mlawer, E. J., Shephard, M. W., Clough, S. A., and Collins, W. D.: Radiative forcing by long-lived greenhouse gases: Calculations with the AER radiative transfer models., J. Geophys. Res., 113, D13, doi:10.1029/2008JD009944, 2008.

Jacob, D., Petersen, J., Eggert, B., Alias, A., Christensen, O. B., Bouwer, L. M., Braun, A., Colette, A., Dq'u,' M., Georgievski, G., Georgopoulou, E., Gobiet, A., Menut, L., Nikulin, G., Haensler, A., Hempelmann, N., Jones, C., Keuler, K., Kovats, S., Kröner, N., Kotlarski, S., Kriegsmann, A., Martin, E., van Meijgaard, E., Moseley, C., Pfeifer, S., Preuschmann, S., Radermacher, C., Radtke, K., Rechid, D., Rounsevell, M., Samuelsson, P., Somot, S., Soussana, J.-F., Teichmann, C., Valentini, R., Vautard, R., Weber, B., , and Yiou, P.: EURO-CORDEX: New high-resolution climate change projec- tions for European impact research, Reg. Environ. Change, 14, 563-578, doi:10.1007/s10113-013-0499-2, 2014.

Jimenéz, P., Dudhia, J., Fidel González-Rouc, F., Navarro, J., Montávez, J., and Garcia-Bustamante, E.: A Revised Scheme for the WRF Surface Layer Formulation, Mon. Weather Rev., 140, 898 918, 2012.

Jones, P. W.: First- and Second-Order Conservative Remapping Schemes for Grids in Spherical Coordinates, Mon. Weather Rev., 127, 2204-2210, doi:10.1175/15200493(1999)127<2204:FASOCR>2.0.CO;2, 1999.

Joyce, R. J., Janowiak, J. E., Arkin, P. A., and Xie, P.: CMORPH: A Method that Produces Global Precipitation Estimates from Passive Microwave and Infrared Data at High Spatial and Temporal Resolution, J. Hydrometeorol., 5, 487-503, 2004.

Kain, J. S.: The Kain-Fritsch Convective Parameterization: An update, J. Appl. Meteor., 43, 170-181, 2004.

Kotlarski, S., Keuler, K., Christensen, O. B., Colette, A., Déqué, M., Gobiet, A., Goergen, K., Jacob, D., Lüthi, D., van Meijgaard, E., Nikulin, G., Schär, C., Teichmann, C., Vautard, R., Warrach-Sagi, K., and Wulfmeyer, V.: Regional climate modeling on European scales: a joint standard evaluation of the EUROCORDEX RCM ensemble, Geosci. Model Dev., 7, 1297-1333, doi:10.5194/gmd-7-1297-2014, 2014.

Laprise, R., de Elia, R., Caya, D., Biner, S., Lucas-Picher, P., Diaconescu, E., Leduc, M., Alexandru, A., and Separovic, L.: Challenging some tenets of Regional Climate Modelling, Meteorol. Atmos. Phys., 100, 3-22, doi:10.1007/s00703-008-0292-9, 2008.

Liu, Z., Duan, Z., Jian, J., and Zhu, A.: Evaluation of Three Satellite Precipitation Products TRMM 3B42, CMORPH, and PERSIANN over a Subtropical Watershed in China., Advances in Meteorology, 2015, 13 pp., 2015.

Milovac, J., Ingwersen, J., and Warrach-Sagi, K.: Soil texture forcing data for the whole world for the Weather Research and Forecasting (WRF) Model of the University of Hohenheim (UHOH) based on the Harmonized World Soil Database (HWSD) at 30 arc-second horizontal resolution, doi:10.1594/WDCC/WRF_NOAH_HWSD_world_TOP_SOILTYP, 2014.

Milovac, J., Warrach-Sagi, K., Behrendt, A., Späth, F., Ingwersen, J., and Wulfmeyer, V.: Investigation of PBL schemes 
combining the WRF model simulations with scanning water vapor DIAL measurements, J. Geophys. Res.-Atmos., 121, 2, doi:10.1002/2015JD023927, 2016.

Miyamoto, Y., Kajikawa, Y., Yoshida, R., Yamaura, T., Yashiro, H., and Tomita, H.: Deep moist atmospheric convection in a subkilometer global simulation, Geophys. Res. Lett., 40, 4922-4926, doi:10.1002/grl.50944, 2013.

Morrison, H., Thompson, G., and Tatarskii, V.: Impact of Cloud Microphysics on the Development of Trailing Stratiform Precipitation in a Simulated Squall Line: Comparison of One- and TwoMoment Schemes, Mon. Weather Rev., 137, 991-1007, 2009.

Nolan, D. S., Stern, D. P., and Zhang, J. A.: Evaluation of Planetary Boundary Layer Parameterizations in Tropical Cyclones by Comparison of In Situ Observations and High-Resolution Simulations of Hurricane Isabel (2003). Part II: Inner-Core Boundary Layer and Eyewall Structure, Mon. Weather Rev., 137, 36753698, 2009.

Pai Mazumder, D., Henderson, D., and Mölders, N.: Evaluation of WRF-forecasts over Siberia: Air mass formation, clouds and precipitation, Open Atmospheric Science Journal, 6, 93-110, 2012.

Palmer, T. N.: Climate extremes and the role of dynamics, P. Natl. Acad. Sci. USA, 110, 5281-5282, doi:10.1073/pnas.1303295110, 2013.

Perkins, S. E., Pitman, A. J., Holbrook, N. J., and McAneney, J.: Evaluation of the AR4 Climate ModelsŚimulated Daily Maximum Temperature, Minimum Temperature, and Precipitation over Australia Using Probability Density Functions, J. Climate, 20, 4356-4376, doi:10.1175/JCLI4253.1, 2007.

Piere, A., von Hardenberg, J., Parodi, A., and Provenzale, A.: Sensitivity of precipitation statistics to resolution, microphysics, and convective parameterization: A case study with the highresolution WRF climate model over Europe, J. Hydrometeorol., 16, 1857-1872, doi:10.1175/JHM-D-14-0221.1, 2015.

Prein, A. F., Gobiet, A., Suklitsch, M., Truhetz, H., Awan, N. K., Keuler, K., and Georgievski, G.: Added value of convection permitting seasonal simulations, Clim. Dynam., 41, 2655-2677, doi:10.1007/s00382-013-1744-6, 2013.

Prein, A. F., Gobiet, A., Truhetz, H., Keuler, K., Goergen, K., Teichmann, C., Maule, C. F., van Meijgaard, E., Dq'u,' M., Nikulin, G., Vautard, R., Colett, A., Kjellström, E., and Jacob, D.: Precipitation in the EURO-CORDEX $0.11^{\circ}$ and $0.44^{\circ}$ simulations: High resolution, high benefits?, Clim. Dynam., 46, 383-412, doi:10.1007/s00382-015-2589-y, 2015a.

Prein, A. F., Langhans, W., Fosser, G., Ferrone, A., Ban, N., Goergen, K., Keller, M., Tölle, M., Gutjahr, O., Feser, F., Brisson, E., Kollet, S., Schmidli, J., van Lipzig, N. P. M., and Leung, R.: A review on regional convection-permitting climate modeling: Demonstrations, prospects, and challenges, Rev. Geophys., 53, 323-361, doi:10.1002/2014RG000475, 2015b.

Rabier, F., Järvinen, H., Klinker, E., Mahfouf, J.-F., and Simmons, A.: The ECMWF operational implementation of fourdimensional variational assimilation. I: Experimental results with simplified physics, Q. J. Roy. Meteorol. Soc., 126, 1143-1170, doi:10.1002/qj.49712656415, 2000.

Rasmussen, R. M., Geresdi, I., Thompson, G., Manning, K., and Karplus, E.: Freezing Drizzle Formation in Stably Stratified Layer Clouds: The Role of Radiative Cooling of Cloud Droplets, Cloud Condensation Nuclei, and Ice Initiation, J. Atmos. Sci., 59, 837-860, 2002.
Rogers, J. C.: North Atlantic Storm Track Variability and Its Association to the North Atlantic Oscillation and Climate Variability of Northern Europe, J. Climate, 10, 1635-1647, doi:10.1175/15200442(1997)010<1635:NASTVA>2.0.CO;2, 1997.

Schwitalla, T. and Wulfmeyer, V.: Radar data assimilation experiments using the IPM WRF Rapid Update Cycle, Meteorol. Z., 23, 79-102, 2014.

Schwitalla, T., Bauer, H.-S., Wulfmeyer, V., and Zängl, G.: Systematic errors of QPF in low-mountain regions as revealed by MM5 simulations, Meterol. Z., 17, 903-919, 2008.

Schwitalla, T., Bauer, H.-S., Wulfmeyer, V., and Aoshima, F.: Highresolution simulation over central Europe: assimilation experiments during COPS IOP 9c, Q. J. Roy. Meteorol. Soc., 137, 156175, 2011.

Shin, H. H. and Hong, S.-Y.: Intercomparison of Planetary Boundary-Layer Parametrizations in the WRF Model for a Single Day from CASES-99, Bound.-Lay. Meteorol., 139, 261-281, doi:10.1007/s10546-010-9583-z, 2011.

Skamarock, W. C., Klemp, J. B., Dudhia, J., Gill, D., Barker, D. O., Duda, M. G., Wang, W., and Powers, J. G.: A Description of the Advanced Research WRF Version 3, NCAR Technical Note TN-475+STR, NCAR, Boulder/CO., available at: http://www2. mmm.ucar.edu/wrf/users/docs/arw_v3.pdf, 2008.

Skok, G., Žagar, N., Honzak, L., Žabkar, R., Rakovec, J., and Ceglar, A.: Precipitation intercomparison of a set of satelliteand raingauge-derived datasets, ERA Interim reanalysis, and a single WRF regional climate simulation over Europe and the North Atlantic, Theoretical and Appl. Climatol., 123, 217-232, doi:10.1007/s00704-014-1350-5, 2016.

Stampoulis, D., Anagnostou, E., and Nikolopoulos, E.: Assessment of High-Resolution Satellite-Based Rainfall Estimates over the Mediterranean during Heavy Precipitation Events, J. Hydrometeorol., 14, 1500-1514, 2013.

Tao, W. K. and Simpson, J.: The Goddard cumulus ensemble model. Part I: Model description., Terr. Atmos. Oceanic Sci., 4, 19-54, 1993.

Taylor, K. E., Stouffer, R. J., and Meehl, G. A.: An Overview of CMIP5 and the Experiment Design, B. Am. Meteorol. Soc., 93, 485-498, doi:10.1175/BAMS-D-11-00094.1, 2012.

Vautard, R., Gobiet, A., Jacob, D., Belda, M., Colette, A., Déqué, M., Fernández, J., García-Díez, M., Goergen, K., Güttler, I., Halenka, T., Karacostas, T., Katragkou, E., Keuler, K., Kotlarski, S., Mayer, S., Meijgaard, E., Nikulin, G., Patarčić, M., Scinocca, J., Sobolowski, S., Suklitsch, M., Teichmann, C., Warrach-Sagi, K., Wulfmeyer, V., and Yiou, P.: The simulation of European heat waves from an ensemble of regional climate models within the EURO-CORDEX project, Clim. Dynam., 41, 2555-2575, doi:10.1007/s00382-013-1714-z, 2013.

Warrach-Sagi, K., Wulfmeyer, V., Grasselt, R., Ament, F., and Simmer, C.: Streamflow simulations reveal the impact of the soil parameterization, Meteorol. Z., 17, 751-762, 2008.

Warrach-Sagi, K., Schwitalla, T., Wulfmeyer, V., and Bauer, H.-S.: Evaluation of a climate simulation in Europe based on the WRFNOAH Model System: precipitation in Germany, Clim. Dynam., 41, 755-774, doi:10.1007/S00382-013-1727-7, 2013.

Wulfmeyer, V. and Coauthors: New Concepts for Studying Land-Surface-Atmosphere Feedback Based on a new Lidar Synergy and Grey Zone Simulations, Geophysical Research 
Abstracts, 17, http://meetingorganizer.copernicus.org/EGU2015/ EGU2015-5054.pdf, 2015.

Wulfmeyer, V., Behrendt, A., Kottmeier, C., Corsmeier, U., Barthlott, C., Craig, G. C., Hagen, M., Althausen, D., Aoshima, F., Arpagaus, M., Bauer, H.-S., Bennett, L., Blyth, A., Brandau, C., Champollion, C., Crewell, S., Dick, G., DiGirolamo, P., Dorninger, M., Dufournet, Y., Eigenmann, R., Engelmann, R., Flamant, C., Foken, T., Gorgas, T., Grzeschik, M., Handwerker, J., Hauck, C., Höller, H., Junkermann, W., Kalthoff, N., Kiemle, C., Klink, S., König, M., Krauss, L., Long, C. N., Madonna, F., Mobbs, S., Neininger, B., Pal, S., Peters, G., Pigeon, G., Richard, E., Rotach, M. W., Russchenberg, H., Schwitalla, T., Smith, V., Steinacker, R., Trentmann, J., Turner, D. D., van Baelen, J., Vogt, S., Volker, H., Weckwerth, T., Wernli, H., Wieser, A., and Wirth, M.: The Convective and Orographically Induced Precipitation Study (COPS): The Scientific Strategy, the Field Phase, and research Highlights, Q. J. Roy. Meteorol. Soc., 137, 3-30, 2011.

Wulfmeyer, V., Muppa, S. K., Behrendt, A., Hammann, E., Späth, F., Sorbjan, Z., Turner, D. D., and Hardesty, R. M.: Determination of Convective Boundary Layer Entrainment Fluxes, Dissipation Rates, and the Molecular Destruction of Variances: Theoretical Description and a Strategy for Its Confirmation with a Novel Lidar System Synergy, J. Atmos. Sci., 73, 667-692, doi:10.1175/JAS-D-14-0392.1, 2016.
Xie, Z., Du, Y., and Yang, S.: Zonal Extension and Retraction of the Subtropical Westerly Jet Stream and Evolution of Precipitation over East Asia and the Western Pacific, J. Climate, 28, 67836798, doi:10.1175/JCLI-D-14-00649.1, 2015.

Žagar, N., Honzak, L., Žabkar, R., Skok, G., Rakovec, J., and Ceglar, A.: Uncertainties in a regional climate model in the midlatitudes due to the nesting technique and the domain size, J. Geophys. Res., 118, 6189-6199, 2013.

Zhang, G., Zhou, G., Chen, F., Barlage, M., and Xue, L.: A trial to improve surface heat exchange simulation through sensitivity experiments over a desert steppe site., J. Hydrometeorol., 15, 664-684, 2014. 